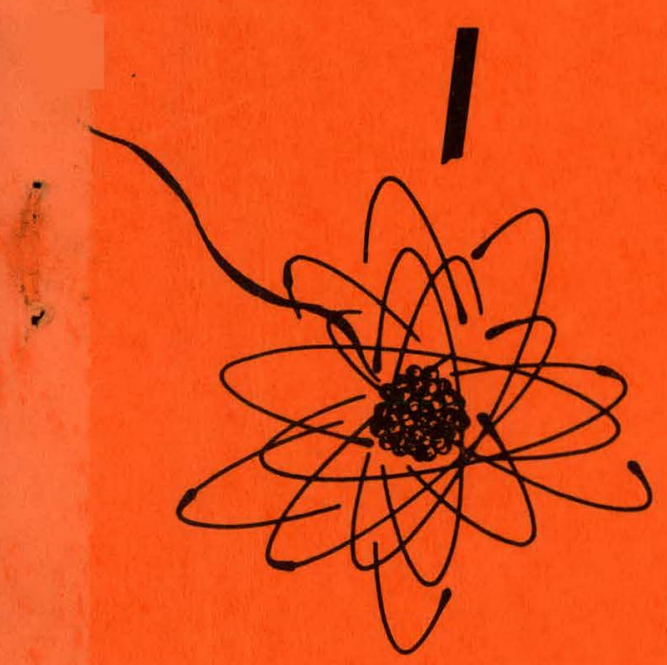

YAEC - 64

\author{
YANKEE ATOMIC ELECTRIC COMPANY
}

RESEARCH AND DEVELOPMENT PROGRAM

\title{
INSPECTION AND FABRICATION YAEC CRITICAL EXPERIMENT FUEL RODS
}

R\&D SUBCONTRACT NO.I Under

USAEC-YAEC CONTRACT AT $(30-3)-222$

MARCH 31, 1958

\section{WESTINGHOUSE ELECTRIC CORPORATION ATOMIC POWER DEPARTMENT \\ PITTSBURGH, 30 \\ P. $0.80 \times 355$ \\ PENNSYLVANIA}

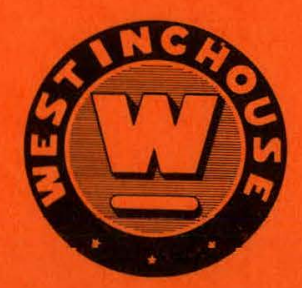

636 


\section{DISCLAIMER}

This report was prepared as an account of work sponsored by an agency of the United States Government. Neither the United States Government nor any agency Thereof, nor any of their employees, makes any warranty, express or implied, or assumes any legal liability or responsibility for the accuracy, completeness, or usefulness of any information, apparatus, product, or process disclosed, or represents that its use would not infringe privately owned rights. Reference herein to any specific commercial product, process, or service by trade name, trademark, manufacturer, or otherwise does not necessarily constitute or imply its endorsement, recommendation, or favoring by the United States Government or any agency thereof. The views and opinions of authors expressed herein do not necessarily state or reflect those of the United States Government or any agency thereof. 


\section{DISCLAIMER}

Portions of this document may be illegible in electronic image products. Images are produced from the best available original document. 
Yankee Atomic Electric Company.

Research And Development Program

INSPECTION AND FABRICATION OF

YAEC CRITICAL EXPERIMENT FUEL RODS

\section{Prepared by}

D. G. Brunstetter

Nuclear Core Engineering

For The Yankee Atomic Electric Company

Under Research and Development Subcontract

No. 1 of USAEC-YAEC Contract AT(30-3)-222

March 31, 1958

\section{WARRANTY}

The Weatinghouse Electric Corporation, Goverament Agenclea, Prine Contractors, Sub-Contractors, or thelr Rcpresentatives or ot her agencles make ao representation or warranty as to the accuracy or usefulnesa of the inforunation or otatementi contained in thls report, or that the use of ang information, apparatus, wethod or process disclosed in this report may not infringe privately-owned rights. No assumption of Lablilty is assumed with respect to the use of. or tor damageg regulting Irom the use of, ary Inlormation, apparatus, method or process dlsclosed in thits report:

\section{Westinghouse \\ ELECTRIC CORPORATION \\ ATOMIC POWER DEPARTMENT \\ P.O. BOX 358 \\ PITTSEURGH 3O, PA.}




\section{EXTERNAL DISTIRIBUTION}

USAEC, Schenectady Operations Office - P. O. Box 1069, Schenectady, N.Y. 4 USAEC, Division of Reactor Development - $1717 \mathrm{H}$ Street, Washington 25, D.C. 8 USAEC, Commissioner, Patent Branch - Washington 25, D.C.

USAEC, Technical Information Service Extension-P.0. Box 62, Oak Ridge, Tenn.20 Yankee Atomic Electric Company - 441 Stuart Street, Boston 16, Mass. . 22

Yankee Atomic Electric Company - c/o Westinghouse Atomic Power Department 1 Pittsburgh 30, Pa. (Representat1ve at Westinghouse APD - Mr. W. J. Miller)

Total

Standard Distribution under Category "Reactors-Power", as provided in TID 4500 , 14th Edition, to be made by TISE, Oak Ridge, Tenn.

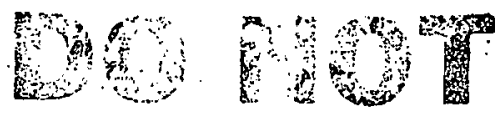

\section{WESTINGHOUSE DIGIRIBUTITON}

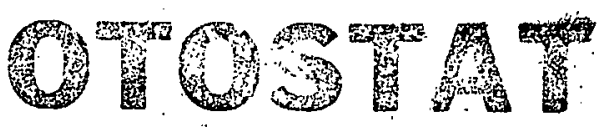

R. I. We.lls - W. E. Shoupp

W. Dee Shepherd

A. E. Voysey

I. H. Coen

W. E. Abbott

J. F. Chalupa

R. L. Witzke

S. M. Marshall

C. F. Obermesser

E. Schafer

H. E. Walchli

Technical Information Center
R. L. Stoker

i. L. Budge

A. R. Del Campo

V. E. Johnson

I. I. Morris - M. A. Schultz

13. 33. Haga

H. L. Russo

H. W. P. Stanhope

H. A. Smith.

R. H. Hartley

(Fng. Mgr. - New York

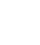


Page No.

List of Figures

List of Tables

I. Abstract

II. Introduction

III. Uranium Dioxide Powder Inspection . 9

IV. Stainless Steel Component Inspection $\quad 14$

A. 'l'ubes $\quad 14$

B. Tnd Plugs 30

V. Uranium Dioxide Pellet Inspection 37

VI. Manufacture of Fuel Rods . 47

A. Tube Loading 47

B. Welding End Plugs into Tubes . 58

C. Inspection of Welds 64

VII. Summary $\quad 69$

$\begin{array}{lll}\text { VIII. Acknowledgements } & 70\end{array}$ 
Figure No.

Page No.

1

Critical Experiment Fuel Rod and Components

'Accountability Procedure

Fuel Tube Drawing

Measurement of Tube Outside Diameter

Distribution Curve of Tube Inside Diameters

Distribution Curve of Tube Outside Diameters

Measurement of Tube Wall Thickness.

Distribution Curve of Tube Wall Thickness

(Vidigage Measurements)

Distribution Curve of Tube Length Measurements

Testing Tube Tntegrity

Typlcal Defect Found by Eddy Current Test

Type A Fuel Assembly Drawing

Type E Fuel Assembly Drawing

Type F Fuel Assembly Drawing

Four-Tube Fuel Assembly Drawing

Control Rod Cross Fuel Bundle Drawing

End Plug Drawing

End Plug Drawing

Distribution Curves for End Plug Insert Diameters.

Pellet Inspection Data Card

40

Pellet Drawing

Measurement of Pellet Length and Diameter

Distribution Curve of Pellet Diameters

Distrihution Curve of l'ellet Lengths

Distribution Curve of Peliet Weights

Equipment for Density Determinations

50

Distribution Curve of Pellet Densities

Tube Loading Data Card

Upright Pellet Loader

Pellet Alignment Equipmerit $\quad 56$

Pellet Loading Equipment ‥ 57

Distribution Curve of Weights of Fuel in Rods 59

Distribution Curve of Lengths of Fuel in Rods 60 


\section{LIST OF FIGURES (cont'd)}

Figure No.

Page No.

Welding of Fuel Rod End Plug

63

35

Fuel Rods Being Inserted in X-ray Machine

66

36

Fuel Rods Ready for X-ray

67

37

Veld Inspection Examples.

68 
I'able No.

Page No.

Procedure for Sampling $\mathrm{UO}_{2}$ Powder for Chemical

$$
\text { finslysis }
$$

III

Analysis of To Porder for Yankee $\mathrm{Crx}$

$\mathrm{UO}_{2}$ (2.7\% Inriched in U-235) Inventory $\mathrm{NBA}$ it

13

IV

Nominal Chemical Analysis of I'ubes

14

Tube Inspection Data Summary

19

$\mathrm{VI}$

Calculated ve. Vidigage Wall Thickness Measurements

19

VII

Tube Length and Weight Data.

21

Macroscopic Cross Section Calculations of Foreign

25

Material on As-Received CRX Tubes

IX

Cleaning Procedure for CRX lubes

27

Analysis of Foreign Material on Tubes

28

Andysis of Detergent

29

Inspection Data Summary- Jype A Fuel Rod End

Plug (Long)

XIII

Inspection Data Summary-Type A. Fuel Rod End

Plug (Short).

XIV.

Inspection Data Summary-Type B Truel Rod End Plug:

30

Evolution of Pellet Sampling Plan

38

$\mathrm{XV}$

Pellet Inspection Data Summary

38

$X V I$

Nomograph vs. Calculated Density Data

41

XVII

Procedure for Determining Density of $\mathrm{UO}_{2}$ Pellets

XVIII

by the Wet Density Method

48

Calculated vs. Wet Densities

49

$\mathrm{UO}_{2}$ Pellet Analysiz

CRX Manufacturing Procedure

52

Fuel Rod Inspection Data Summary

58

Procedure for End Closures for lype CRX Stainless

61 Steel Fuel Tubes for Radioactive Systems

XXIV

Defect Log

$6 \varepsilon$

Procedure for Radiographic Inspection of End

65 Closure Weldments 


\section{Abstract}

The 5509 fuel rods (including 204 special rods) for the Yankee Atomic Electric Company critical experiment were made by sealing sintered UO, pellets in stainless steel tubing by welding end plugs to each end of the steel tubes.

The complete history of the fabrication of these fuel rods from the receipt of pellats to the radiographic inspection of the completed rods is discussed in detail. The control of the quality of the UO powder was exercised by comparing certified analyses upplied by the vendor with analyses made by APD on corresponding lots. Chemical analyses, inspection data, procedures and processes are presented in tables and graphs. 
II. Introduction

The fuel rods for the Yankee critical experiment were made from Type 304 weldrawn stainless steel tubes, 49.4" long. Approximately 80 uranium dioxide (enriched in U-235 to $2.7 \%$ ) pellets $0.6^{\prime \prime}$ long and $0.3^{\prime \prime}$ in diameter were loaded in each tube. The tube was sealed by welding plugs having various configurations to each end (Figure 1 ):

A total of 5509 fuel rods, including 204 special fuel rods, were manufactured and shipped to the Westinghouse Reactor Evaluation Center (WREC) at Waltz Mills, $\mathrm{Pa}$.

The history of component inspection and fabrication of the fuel rods is presented in this report.

Approved $A E C$ transfer and accountability procedures were used to accóunt for all the $2.7 \%$ enriched uranium dioxide for this project. A balance sheet of the uranium dioxide in the form of acceptable pellets received. for the manufacture of CRX fuel. rods is presented.

A comparison is made of the results of chemical analyses of uranium dioxide made at the powder vendor's laboratory and as-received. Sintered. pellets were also analyzed. Analyses were made of sintered material rejected because of dimensions and physical appearance and of accejtible material.

Inspection equipment was calibrated with the use of secondary standards that were referenced to primary standards. For example, a precisely machined stainless steel pellet was obtained whose dimensions were held to a tolerance of $+0.00003^{\prime \prime}$. The standard was measured using the accepted U. S. National Bureau of Standards methods.

Inspection vas made of random samples of components. A five percent sample plan was used on metal parts. Exceptions were: 1. a 100 measurement made on the diametipr of the tulue insert section of all end plugs to Insure proper fit-up during the velding operation, 2 . a 100\% length. measurement on certain type end plugs.

The pellet sampling plan is presented in section IV of this report. A sample was extracted from each batch and tested. If all the measurements were within specifications, the batch was accepted. If not, a more thorough analysis was made of the batch in question.

Identification was provided by numbering the fuel rods. The powder and pellet identifications were cross referenced to loaded tube numbers. 


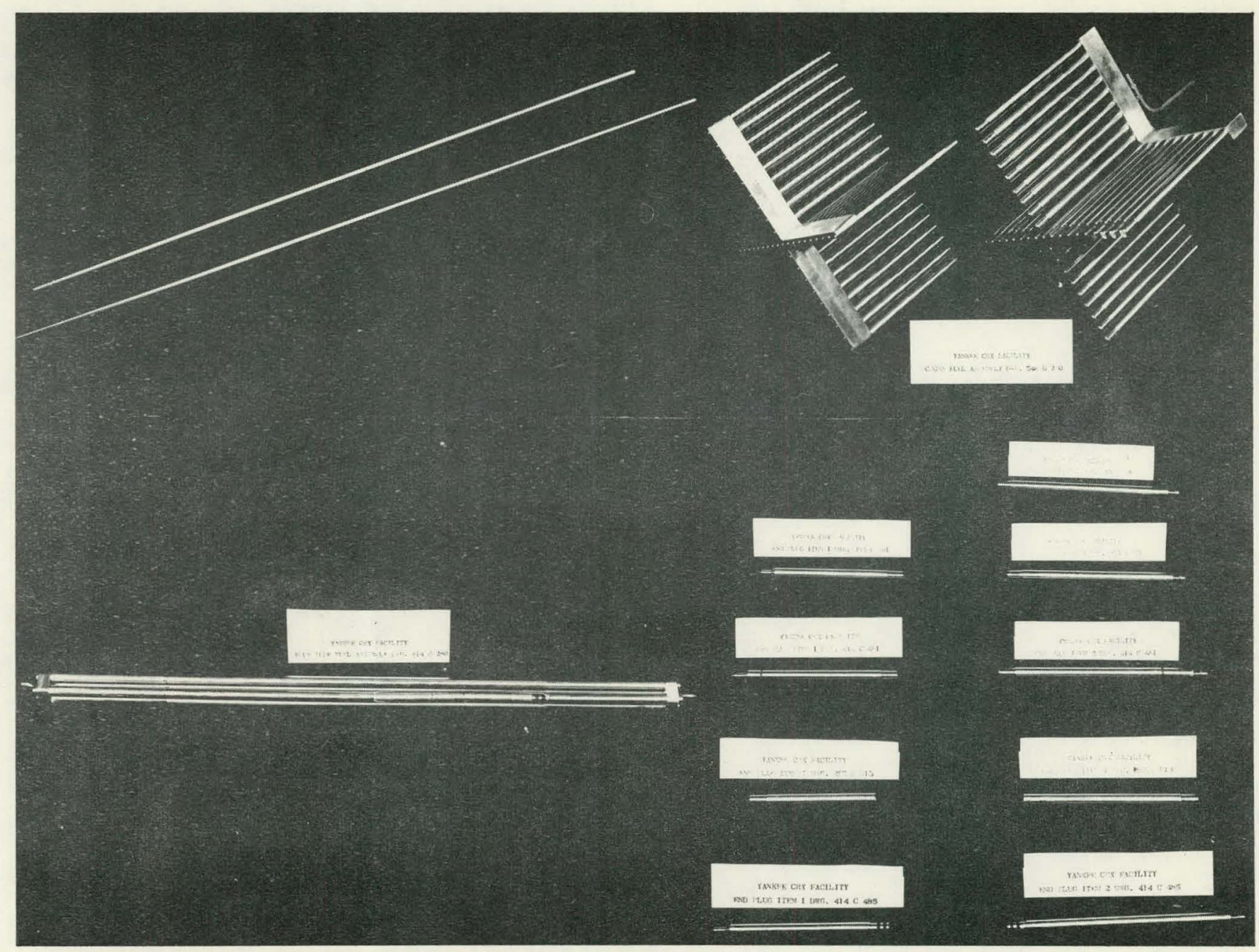

Figure 1

CRITICAL EXPERIMENT FUEL ROD AND COMPONENTS

The completed fuel rod (upper left) contains eighty pellets loaded into the tube (under completed rod) and are sealed (by welding or using 0-rings) with end plugs (drawings are included in this report). The cruciform configuration was formed after welding on special end plugs. 
III. Uranium Dioxide Powder Inspection

The uranium dioxide powder was produced at the Mallinckrodt Chemical Works by the Ammonium Diuranate Process from $2.7 \%$ enriched UF6.

The uranium dioxide powder was shipped (in polyethylene lined fiber-pack drums with a 57 pound capacity) to Westinghouse Materials Manufacturing Department for fabrication into pellets. Each drum was identified with a code designating the cylinder of UF6 from which the powder was produced.

A 150 gram sample was extracted with a thief as each drum was processed using the process show in Table $I$. The samples were combined from drums composing a "lot" and reduced by quartering to 100 grams. The sample of 100 grams was analyzed at WAPD. Results of the analyses by "lots" are compared to the certified analyses made by the vendor in Table II. Excellent agreement was found between these analyses.

Westinghouse MMD received 3,463,409.1 grams of $2.7 \%$ enriched uranium dioxide powder packaged in 136 drums, corresponding to twelve lots. Pellets were placed in polyethylene bags and shipped in one gallon cans. A total of 1015 cans of pellets were received by WAPD. Cans of pellets have been designated and are referred to in this report as "batches". Each batch was identified as shown by the following example:

\begin{tabular}{|c|c|c|}
\hline $\begin{array}{c}\text { Lot Number } \\
\text { LP 15 }\end{array}$ & $\begin{array}{c}\text { Drum } \\
4\end{array}$ & $\begin{array}{c}\text { Can } \\
6\end{array}$ \\
\hline
\end{tabular}

The veight of pellets within the 5509 completed fuel rods was $3,114,733.5$ grams.

The yield of $\mathrm{UO}_{2}$ powder to pellets in completed $\mathrm{CRX}$ fuel rods was:

$$
\frac{3,114,733.5}{3,461,547.5} \times 100=90.0 \% *
$$

The pellet disposition for Material Balance Area $\# 9$, WAPD, Inspection and Manufacturing, is given in labular form (Table III). The production. yield is calculated. The percentage of unaccountable loss incurred during manufacture is also calculated. The disposition is further divided into recoverable and non-returnable material to $\mathrm{MBA}$ t/t9. The recovery of $\mathrm{UO}_{2}$ used for chemical analysis and experimentation is under investigation. A chart of the accountability procedure is shown in Figure 2 .

* Includes loss incurred at $\underline{W} \mathrm{MD}$ and $\mathrm{W}$ APD. 


\section{TABLE I}

Procedure For Sampling $\mathrm{UO}_{2}$ Powder for Chemical Analyses

1. Roll the drum of $\mathrm{UO}_{2}$ fifty feet.

2. Turn the drum end over end several t1mes.

3. Roll the arum back 50 feet.

4. Turn the drum end over end several t1mes.

5. Withdraw flve samples by using a "thlef"or pipe ith holes drilled at vartous distances to insure the extraction of a random sample - one from each cardinal point of the compass and one from the center - about 150 grams total.

6. Mix the samples from all drums in a lot in a polyethylene bag.

7. Reduce the composite sample for the lot to 100 gms by quartering. 
TABLT II

ANALYSIS UO2 POWDER FOR. YAIKEE CRX $M C W=$ MALL INKKFOCT CHEMICAL CO.

占

\begin{tabular}{|c|c|c|c|c|c|c|c|c|c|c|c|c|c|c|c|c|c|c|}
\hline .0T & $\underline{L P}$ & 15 & LP & 16 & is & 17 & LP & 18 & $* z$ & 28 & wz & 46 & & & & & & \\
\hline ASSAY & MCW & $A P O$ & MCH & $A P D$ & NCW & $A P B$ & MCN & $A P D$ & MCH & $A P D$ & MCW & $A P D$ & & & & & & \\
\hline$u \geqq 85.8 \%$ & 88.0 & 88,0 & 87.9 & 87.9 & 87.9 & 87.9 & 88.0 & 87.8 & 87.9 & 88.0 & 87.2 & 87.1 & The a & ccuracy of & determini & ing to & tal u & ranium \\
\hline $\mathrm{VO}_{2} \geqq 95.0$ & 97.5 & 97.5 & 97.6 & 97.2 & 96.2 & 97.0 & 97.9 & 97.8 & 95.9 & 95.0 & 96.7 & 96.9 & is + & $0.1 \%$ & & & & \\
\hline F 500 pent & 50.0 & 10 & 50 & 6 & $<50$ & $<4$ & 50 & 6 & 200 & 106 & 50 & 50 & & & & & & \\
\hline $\mathrm{Fe}$ 105 PPM & 60,0 & 77.0 & 40 & 60 & 30 & 66 & 60 & 82 & 100 & 86 & 100 & 127 & For e & lements re & ported in & ppm t] & he a.c & curacy \\
\hline Ho 1 PPA & 0.4 & $<2.0$ & 0.4 & $<2.0$ & 0.6 & $<2$ & 0.6 & $<2$ & 1 & 0.98 & 0.9 & $<1.0$ & is \pm & $30 \%$ of the & amount pr & gesent & . & \\
\hline B 2 PPY & 0.1 & 0.9 & 0.2 & 0.1 & 0.1 & 0.2 & 0.1 & 0.09 & 0.2 & $<0.1$ & 0.1 & $<0.1$ & & & & & & \\
\hline Cu 40 PPM & 2.0 & 1.0 & 2.0 & 1.0 & 3.0 & 2.0 & 2.0 & 3.0 & 2.0 & 1.3 & 2.0 & 1.0 & & & & & & \\
\hline PO \$O.PPY & 1.0 & 1.1 & 1.0 & 1.2 & 4.0 & 1.1 & 1.0 & 1.8 & 2.0 & 2.1 & 8.0 & 4.8 & & & & & & \\
\hline Cr $40 \mathrm{PPM}$ & 30 & 31 & 20.0 & 19.0 & 30.0 & 42 & 20.0 & 16.0 & 40.0 & 80.0 & 40.0 & 38.1 & & & & & & \\
\hline $\sin 4 p p$ & $<1$ & 0.9 & 1.0 & 1.1 & 1.0 & 1.2 & 1.0 & 1.0 & 1 & .74 & 1 & 1.6 & & & & & & \\
\hline As 1 PPS & 0.01 & $<0.2$ & 0.01 & $<0.2$ & $<0.01$ & C.55 & $<0.01$ & 0.31 & $<0.01$ & $<.5$ & $<0.01$ & $<0.1$ & & & & & & \\
\hline *) 80 PPA & 100 & 78.3 & 100 & 55.3 & 80 & 58 & 100 & 69 & 100 & 65 & 200 & 55.0 & & & & & & \\
\hline $3 i$ & & & & & & & & & & & & 5.1 & & & & & & \\
\hline & & & & & & & & & & & & & & & & & & \\
\hline & & & & & & & & & & & & & & & & & & \\
\hline & & & & & & & & & & & & & & & & & & \\
\hline & & & & & & & & & & & & & & & & & & \\
\hline LoT & Ps & 64 & $R C$ & 76 & $R R$ & $\pi$ & SM & 76 & $T D$ & 79 & & & & & & & AYERAG & \\
\hline Assar & nox & APO & MCW & $\triangle P D$ & Hor & APD & HOX & APO & MCN & $A P D$ & & & & & & & Her & $A P D$ \\
\hline$u>86.88$ & 87.7 & 87.5 & 87.9 & 87.7 & 87.9 & 87.8 & 87.8 & 87.7 & 87.8 & 87.7 & & & & & & & 87.8 & 87.7 \\
\hline $\mathrm{VO}_{2} \geqq 95.0$ & 96.3 . & 96.5 & 96.8 & 96,8 & 96.4 & 96.5 & 95.9 & 95.7 & 95.8 & 96.1 & & & & : & & & 96.7 & 96.6 \\
\hline F $50 \mathrm{PPH}$ & $<50.6$ & 14.0 & 80 & 17.4 & 50 & 21.: & 60 & 24.5 & 50 & 6.8 & & & & & & & 67.3 & 24.3 \\
\hline Fe 160 PPM & 800 & 93.0 & 80. & 105 & 80 & 155 & 50 & 104 & 60 & 151 & & & & & & & 55.8 & 100.5 \\
\hline Ho $\perp$ PPM & 1.0 & 0.8 & 2.0 & 0.8 & 8 & 12 & 0.9 & 1.0 & 1 & 1 & & & & & & & 1.5 & $<1.3$ \\
\hline $8=2$ PPM & 0.1 & $<0.2$ & 0.2 & $<0.2$ & 0.1 & $<0.2$ & 0.1 & $<02$ & 0.2 & $<0.2$ & & & & & & & 0.1 & $<0.2$ \\
\hline Cu 40 PPM & 3.0 & + & 2.0 & 1.6 & 2.0 & 1.4 & 1 & 2.1 & 2.0 & 1.1 & & & & & & & 2.1 & 1.7 \\
\hline Po $40 \mathrm{Per}$ & 8.2 & 4 & 2.0 & 1 & 1.0 & 1.0 & 2 & 2.0 & 1.0 & 1.2 & & & & & & & 2.8 & 1.9 \\
\hline Cr th Py & 20.0 & 22. & 300 & 34 & 30 & 72 & 30 & 24 & -20 & 49 & & & & & & & 28.2 & 34.3 \\
\hline$S=P P M$ & 1.0 & $<1.0$ & 1.0 & $<1.0$ & $<1.0$ & $<1.0$ & $<1$ & $<1$ & $<1$ & $<1.2$ & & & & & & & 1.0 & $<2.6$ \\
\hline As I PPM & $<0.01$ & 0.1 & $<0.01$ & $<0 . t$ & $<0.01$ & $<21$ & $<0.01$ & $<0.1$ & $<0.01$ & $<0.1$ & & & & & & & 0.01 & 0.21 \\
\hline NI 80 PPM & 40 & 55 & so & 59 & 150 & 129 & 150 & 130 & 70 & 128 & & & & & & & 103.6 & 80.2 \\
\hline si & & 23 & & & & 1 & & 21 & & 35 & & & & & & & & \\
\hline
\end{tabular}




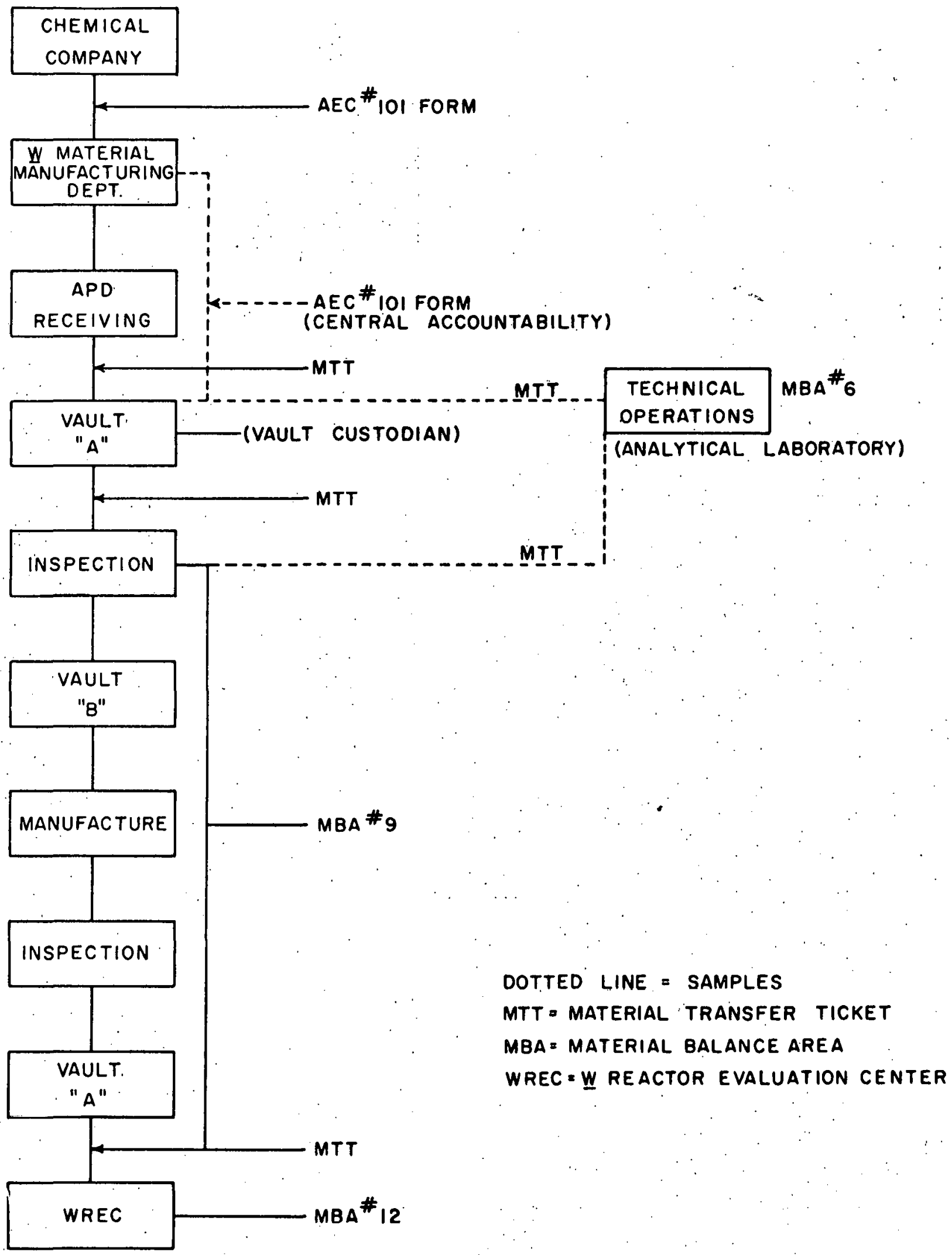

\section{ACCOUNTABILITY PROCEDURE}

Figure 2 
TABLE III

$\mathrm{UO}_{2}(2.7 \%$ Enriched in U-235) Inventory
MBA $\# 9^{*}$

Balance

Total weight of good pellets received at MBA \#9

Shipped to HREC

$3,151,781.0 \mathrm{gms}$

$3,1] 4,733.5 \mathrm{gms}$

$37,047.5 \mathrm{gms}$

Difference is made up of the

foliowing:

Shipped from and not returnable

to MBA \#9

Used in experiments

Chemical Analysis

Irradiation Samples

$\begin{array}{r}3191.5 \mathrm{gms} \\ 7253.9 \mathrm{gms} \\ 4695.0 \mathrm{gms} \\ \hline 15,140.4 \mathrm{gms}\end{array}$

$21,907.1$ gms

Recoverable, being held in

Vault in MBA \#9.

Retained Sample

Generated Scrap

$5944.0 \mathrm{gms}$

Sub-Total.

$\frac{11,904.5 \mathrm{gms}}{17,848.5 \mathrm{gms}}$

4,058.6 gms

Unaccountable loss occurring during fabrication at WAPD: $\quad 4,058.6 \mathrm{gms}$

Yield of pellets in completed rods to pellets received is calculated as follows:

$$
\frac{3,114,733.5}{3,151,781.0} \cdot 98.82 \%
$$

The percentage of unaccountable.loss is calculated as follows:

$$
\frac{4,058.6 \times 100}{3,151,781.0}=0.12 \%
$$

The percentage loss for all other reasons:

$$
\frac{32,988.9}{3,151,781.0}=1.06 \%
$$

* Material Balance Area \#9 at WAPD, Inspection and Manufacturing 
Table II is a comparison of $\mathrm{UO}_{2}$ powder (Lot) analysis certified by the vendor to the receiving inspection analysis.

IV. Stainless Steel Component Inspection

A. Tubes

Type 304 veldraw stainless steel tubing was used for the cladding of the CRX fuel rods (W draving 295B904-1) Figure 3 .

A nominal wall thickness of .0165" and a nominal inside diameter of $0.3060^{\prime \prime}$ were specified. The tubing received from the Trent Tube Company had a nominal chemical analysis as follows:

TABLE IV

Nominal Chemical Analysis of Tubes

\begin{tabular}{|c|c|}
\hline Element & Percent \\
\hline $\mathrm{C}$ & .06 \\
$\mathrm{Mn}$ & 1.23 \\
$\mathrm{P}$ & .03 \\
$\mathrm{~S}$ & .0 .15 \\
$\mathrm{Si}$ & .50 \\
$\mathrm{Vi}$ & 9.58 \\
$\mathrm{Cr}$ & 18.20 \\
$\mathrm{Mo}$ & .23 \\
$\mathrm{Cu}$ & .35 \\
\hline
\end{tabular}

A random 5\% tube sample was inspected for length, inside diameter, outside diameter, wall thickness, length, weight and integrity.

Each tube of the sample was measured at six locations along its length to obtain a minimum and maximum dimension for both inside and outside diameters. A Federal Dimensionair, Model DA-l, graduated in $0.00005^{\prime \prime}$ increments was used. The gage was standardized with the use of master setting plugs and rings. Figure 4 shows the measurement of the OD of a CRX fuel tube.

Ovality (deviation from a true circle) was calculated from the maximum and minimum diameter readings for both the inside diameter and the outside diameter. The accumulated data is summarized in Table V. Figures 5 and 6 are the frequency distribution curves for the inside and outside diameter measurements, respectively. 


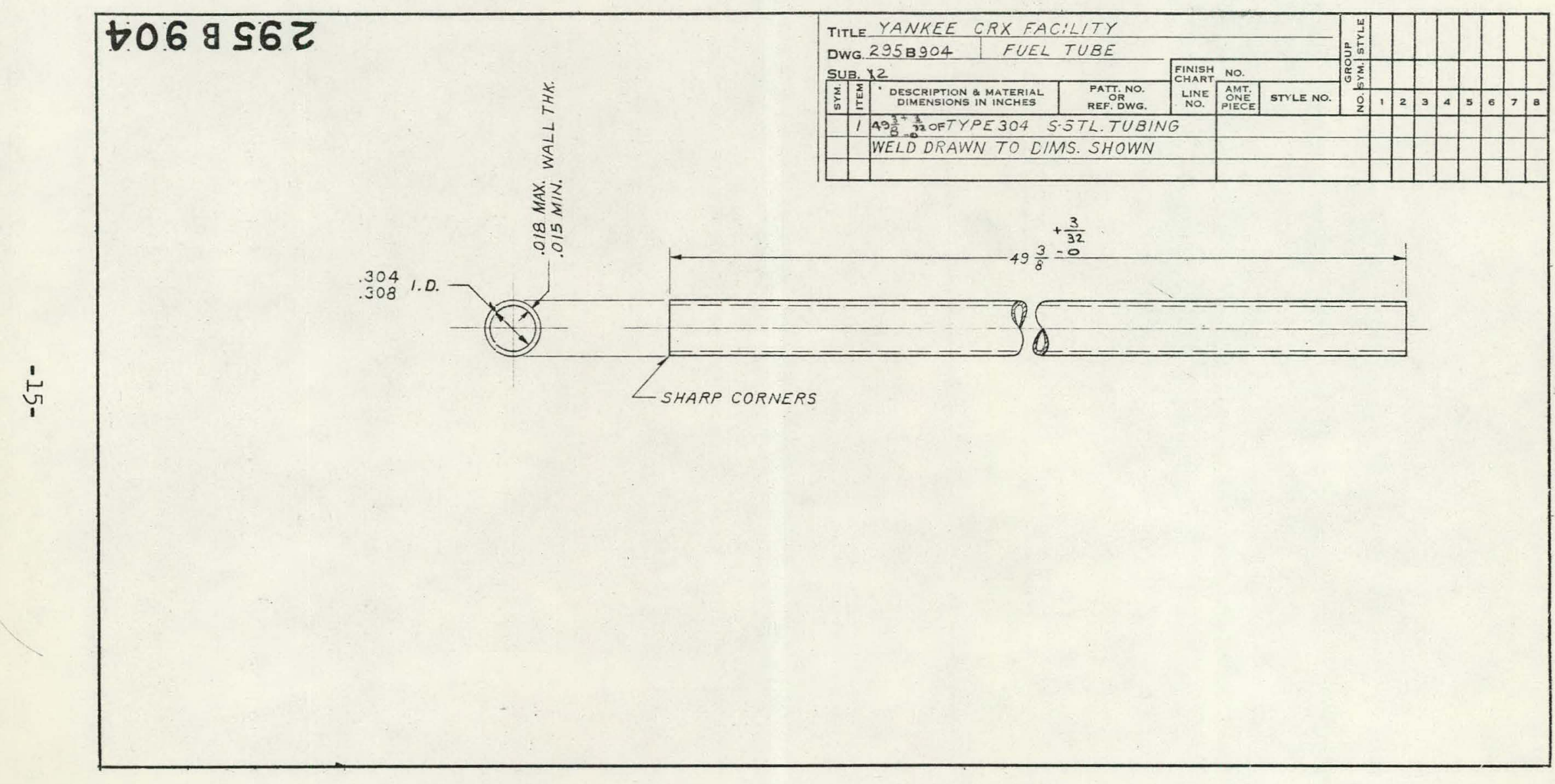




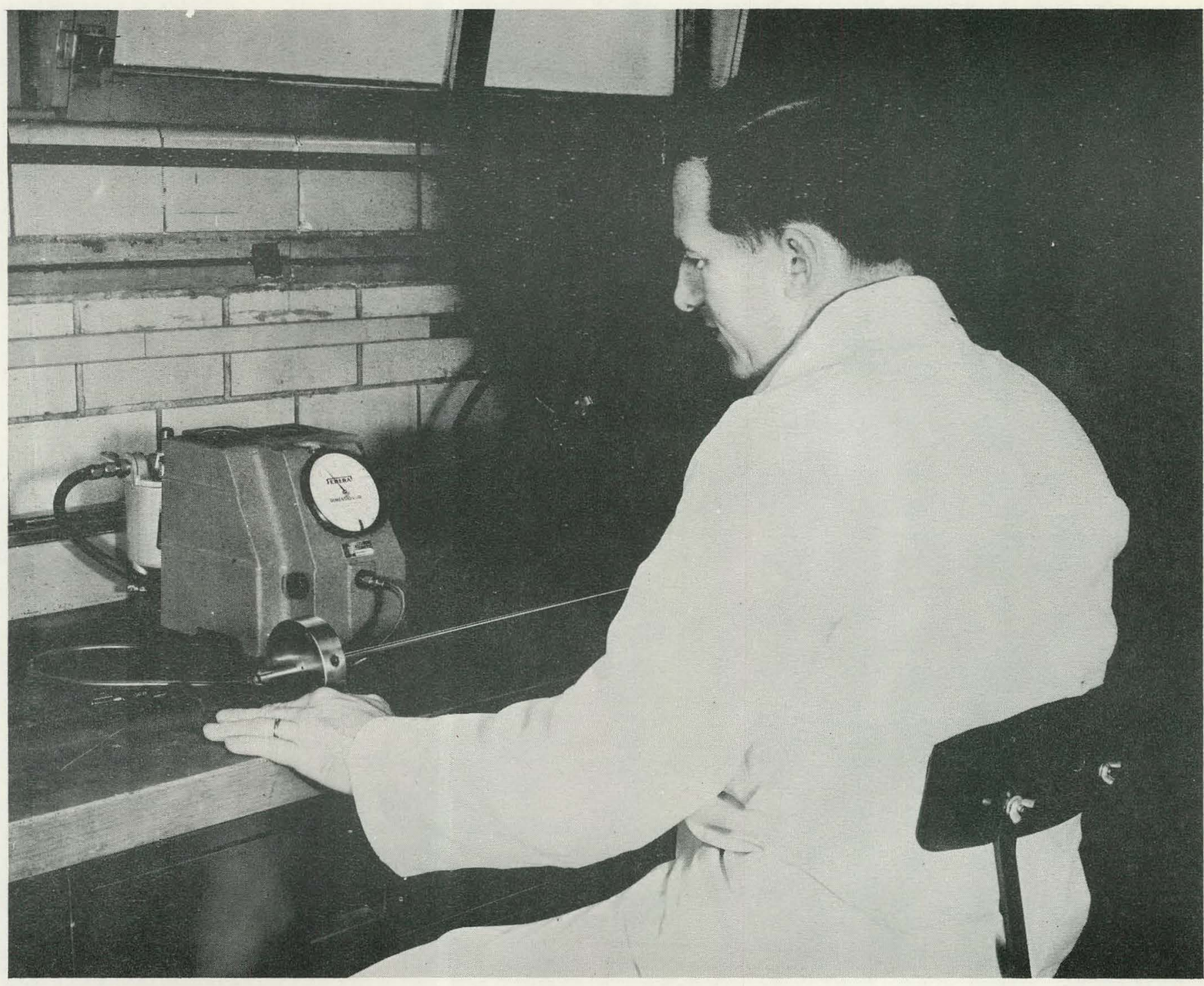

Figure 4

MEASUREMENT OF TUBE OUTSIDE DIAMETER

The measurement of the outside diameter of a CRX tube using an air gage. Inside measurements are made using a two-jet air plug in place of the ring pictured above. 


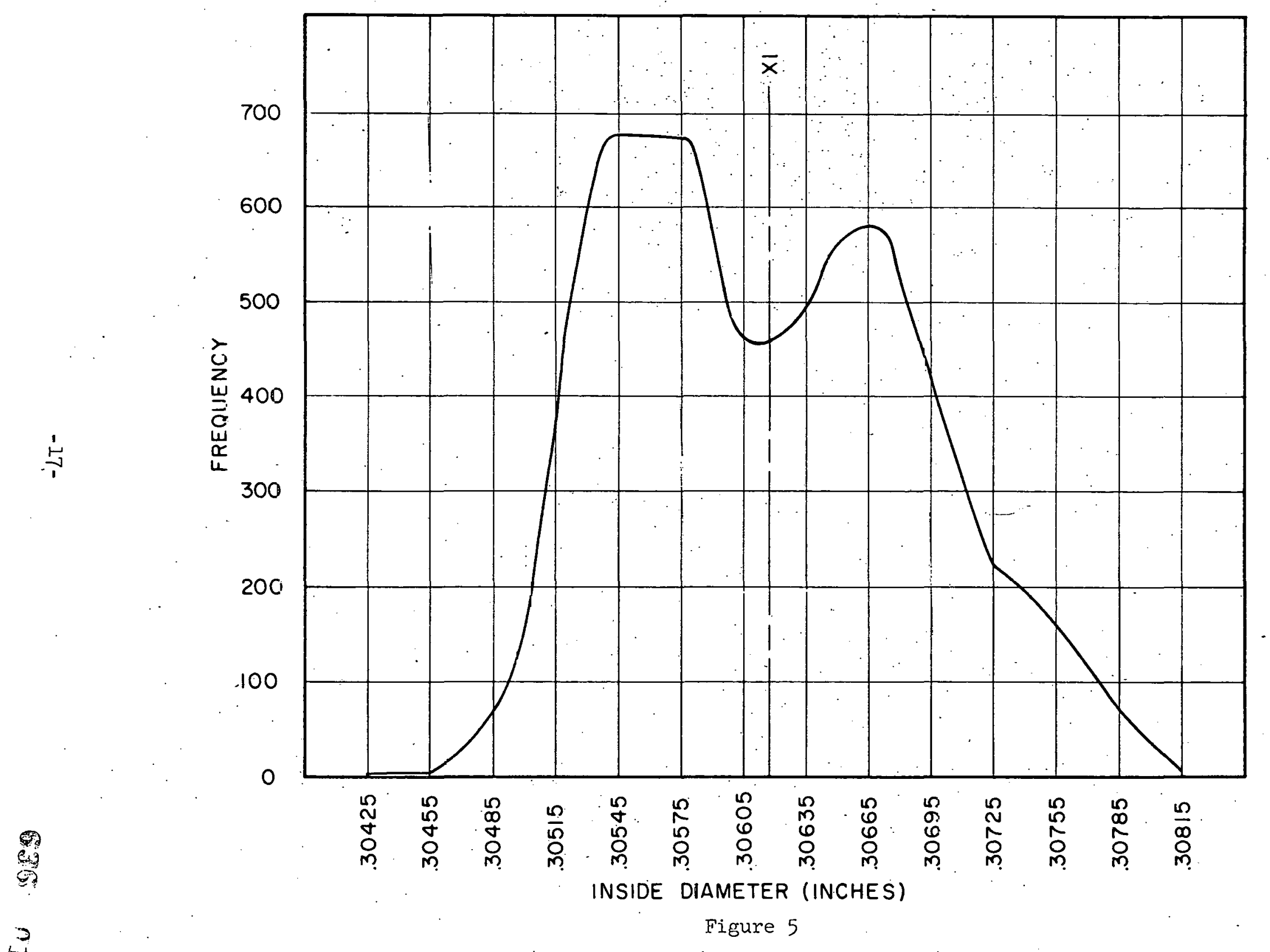

48

DISTRLBUTION: CURVE OF TUBE INSIDE DIAMETERS 


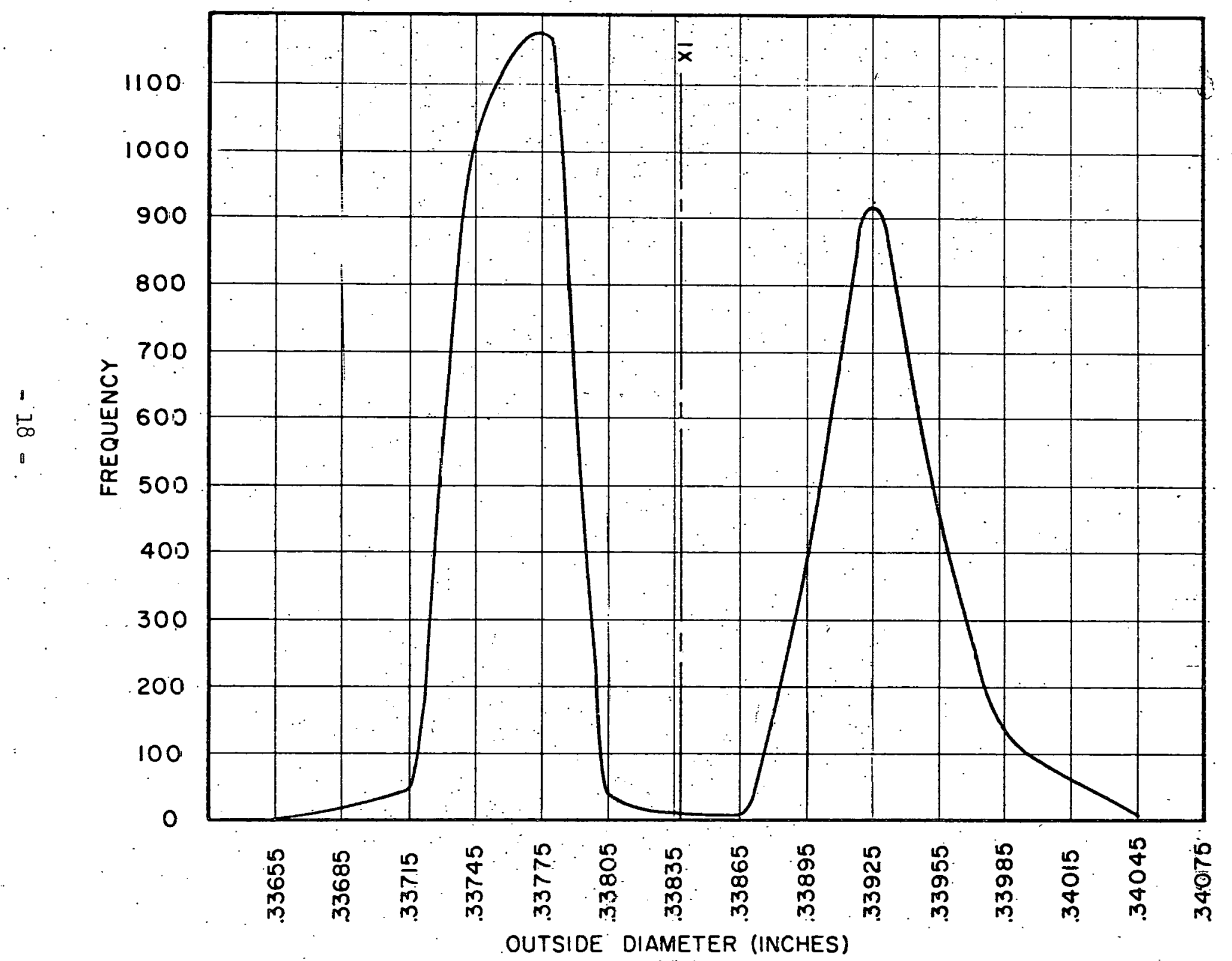

Figure 6

DISTRIBUTION CURVE OF TUBE OUTSIDE DIAMETERS 
Tube Inspection Data Summary

\begin{tabular}{|l|l|l|l|l|}
\hline Variable & OD & ID & OD Ovality & ID Ovality \\
\hline Maximum & $0.34045^{\prime \prime}$ & $0.30815^{\prime \prime}$ & $0.00095^{\prime \prime}$ & $0.00095^{\prime \prime}$ \\
Minimum & $0.33655^{\prime \prime}$ & $0.30424^{\prime \prime}$ & $0.00005^{\prime \prime}$ & $0.00005^{\prime \prime}$ \\
Range & $0.00390^{\prime \prime}$ & $0.00391 "$ & $0.00090^{\prime \prime}$ & $0.00090^{\prime \prime}$ \\
Average & $0.33840^{\prime \prime}$ & $0.30616^{\prime \prime}$ & $0.00018^{\prime \prime}$ & $0.00031^{\prime \prime}$ \\
$\sigma$ Fample S1ze & 0.0012 & 0.0009 & 0.00010 & 0.00013 \\
Samp & & 352 & 352 & 352 \\
(Tubes) & 352 & 4224 & 1408 & 1408 \\
No. of Meas. & 4224 & & & \\
\hline
\end{tabular}

The wall thickness of the tubes was measured with a Branson Instrument Company Vidigage (ultrasonic resonance mêthod), Figure 7, Model 21. The Vidigage was calibrated by using a 304 type stainless steel standard (.0165" thick) flat and fine adjustments were made using a measured section of one of the CRX tubes. A 50 - 50 solution of glycerine and water containing two..drops of a wetting agent (Eastman Kodak, Photo-Flo) was used as a couplant. Discrete measurements were made (instead of the usual practice of sliding the unit along the tube surface) to prevent wear of the search unit (transducer). Tube wall thickness measurements made by-using the Vidigage were comparêd to the thickness as calculated from outside diameter measurements, (Table VI.)

TABLE VI

Calculated VS Vidigage Wall Thickness Measurements

\begin{tabular}{|c|c|c|c|c|c|c|}
\hline : & \multicolumn{2}{|c|}{ Sample 1} & \multicolumn{2}{|c|}{ Sample 2} & \multicolumn{2}{|c|}{ Sample 3} \\
\hline & Calc. & Vidi. & Calc. & Vidi. & Calc. & Vidi. \\
\hline $\begin{array}{l}\text { Average } \\
\sigma^{*} . \\
\text { Range. }\end{array}$ & $\begin{array}{l}0.01624 \\
0.00018 \\
0.00080\end{array}$ & $\begin{array}{l}0.01616 \\
0.00015 \\
0.00110\end{array}$ & $\begin{array}{l}0.01592 \\
0.00023 \\
0.00100\end{array}$ & $\begin{array}{l}0.01576 \\
0.00024 \\
0.00120\end{array}$ & $\begin{array}{l}0.01610 \\
0.00014 \\
0.00050\end{array}$ & $\mid \begin{array}{l}0.01603 \\
0.00018 \\
0.00090\end{array}$ \\
\hline
\end{tabular}

\begin{tabular}{|c|c|c|c|}
\hline & & \multicolumn{2}{|c|}{ Combined } \\
\hline & & Calc. & Vidi. \\
\hline $\begin{array}{l}\text { Average } \\
\sigma^{*} \\
\text { Range }\end{array}$ & & $\begin{array}{l}0.01608 \\
0.00027 \\
0.00110\end{array}$ & $\begin{array}{l}0.01596 \\
0.00028 \\
0.00140\end{array}$ \\
\hline
\end{tabular}

* Root Mean Square Deviation

Note: All measurements in inches. 


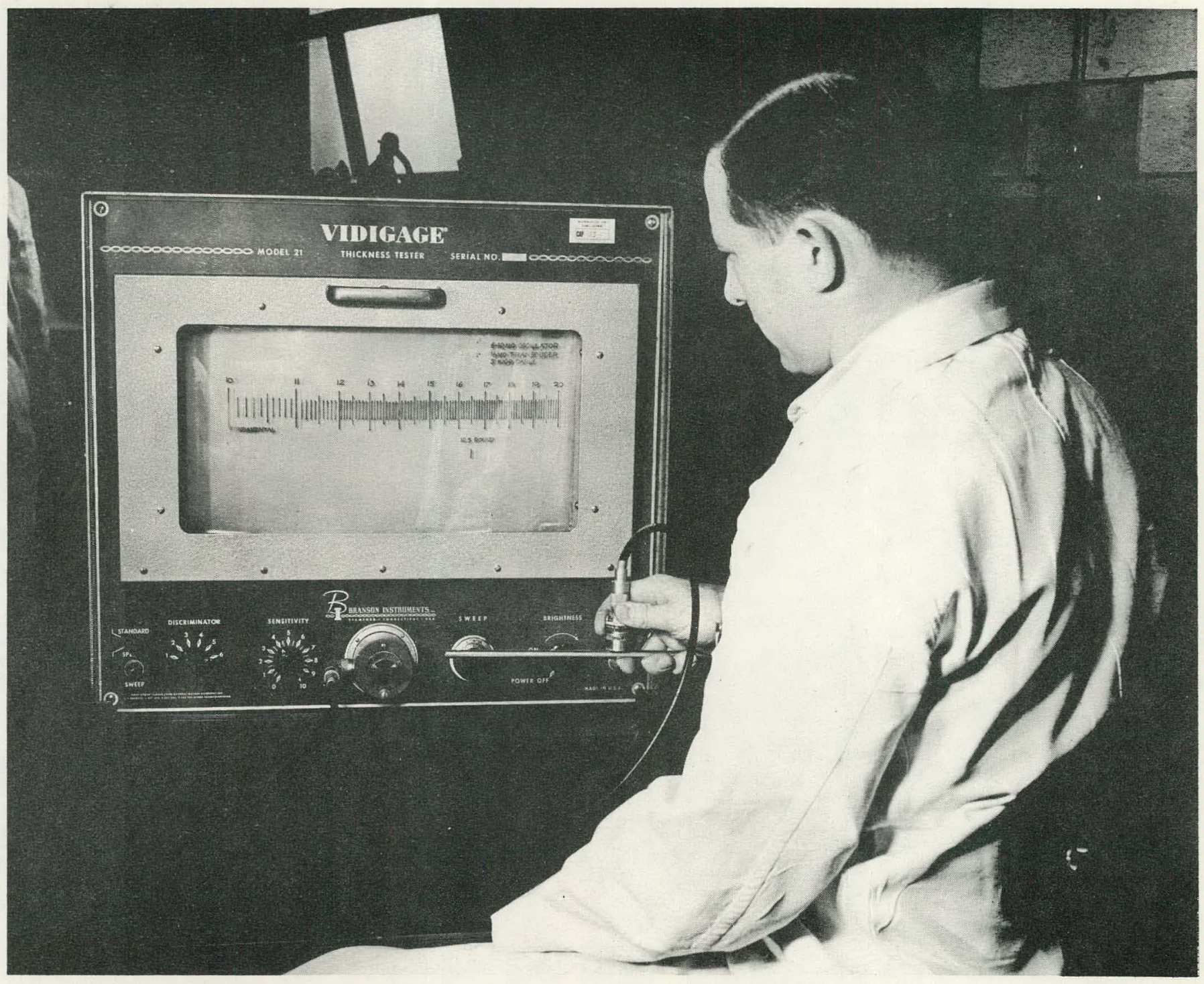

Figure 7

MEASUREMENT OF TUBE WALL THICKNESS

Measurement of the wall thickness of the CRX tube using an ultrasonic resonance method. 
The observed difference is within the sensitivity of the Vidigage. $2 \%$.

Figure 8 is the frequency distribution curve of the Vidigage wall

thickness measurements.

$$
\text { "... }
$$

The length of the tubes was measured with a gage assembly consisting of a " $V$ " block tube holding device and a Federal dial indicator graduated in 0.001 " increments. A stainless steel rod for use as a length standard was calibrated using Bureau of standards methods.

Figure 9 is the frequency distribution curve for the length measurements. A summary of the tube measurements follows:

\section{TABLE VII}

Tube Length and Weight Data

\begin{tabular}{|l|c|c|}
\hline & Length & Weight \\
\hline Maximum & $49.445^{\prime \prime}$ & $107.250 \mathrm{gs}$ \\
Minimum & $49.400^{\prime \prime}$ & $100.250 \mathrm{gs}$ \\
Range & $0.045^{\prime \prime}$ & $7.000 \mathrm{gs}$ \\
Average & $49.420^{\prime \prime}$ & $104.453 \mathrm{gs}$ \\
& 0.0069 & 1.350 \\
Sample Size & 305 & 308 \\
\hline
\end{tabular}

A 5\% sample of as-received tubing was weighed to the nearest 0.001 grams on a Gramatic Balance. A summary of the tube weights obtained is shown above.

The weight in pounds per foot of the stainless steel tubes was calculated as follows:

$$
\begin{aligned}
\frac{49.420 " \text { (aver. length } / \mathrm{rod} \text { ) }}{12^{\prime \prime} / \mathrm{ft}} & =4.110 \mathrm{ft} / \mathrm{rod} \\
\frac{104.453 \mathrm{grams}}{453.6 \mathrm{gm} / \mathrm{lb}} & =0.2303 \mathrm{\#} / \mathrm{rod} \\
\frac{.2303 \mathrm{H} / \mathrm{rod}}{4.110 \mathrm{ft} / \mathrm{rod}} & =0.056 \mathrm{H} / \mathrm{ft} \text { of } \mathrm{s} / \mathrm{s} \mathrm{rod}
\end{aligned}
$$

Approximately 5\% of the CRX tubes were testëd for integrity using a Shell Development Company's Model E Probalog (Eddy Current Tester) Figure 10. Indications of discontinuities were found on $10 \%$ of those tubes tcated. Five of the tubes were sectioned at the indicated area and microphotographed. No attempt: was made at this time to mäke 


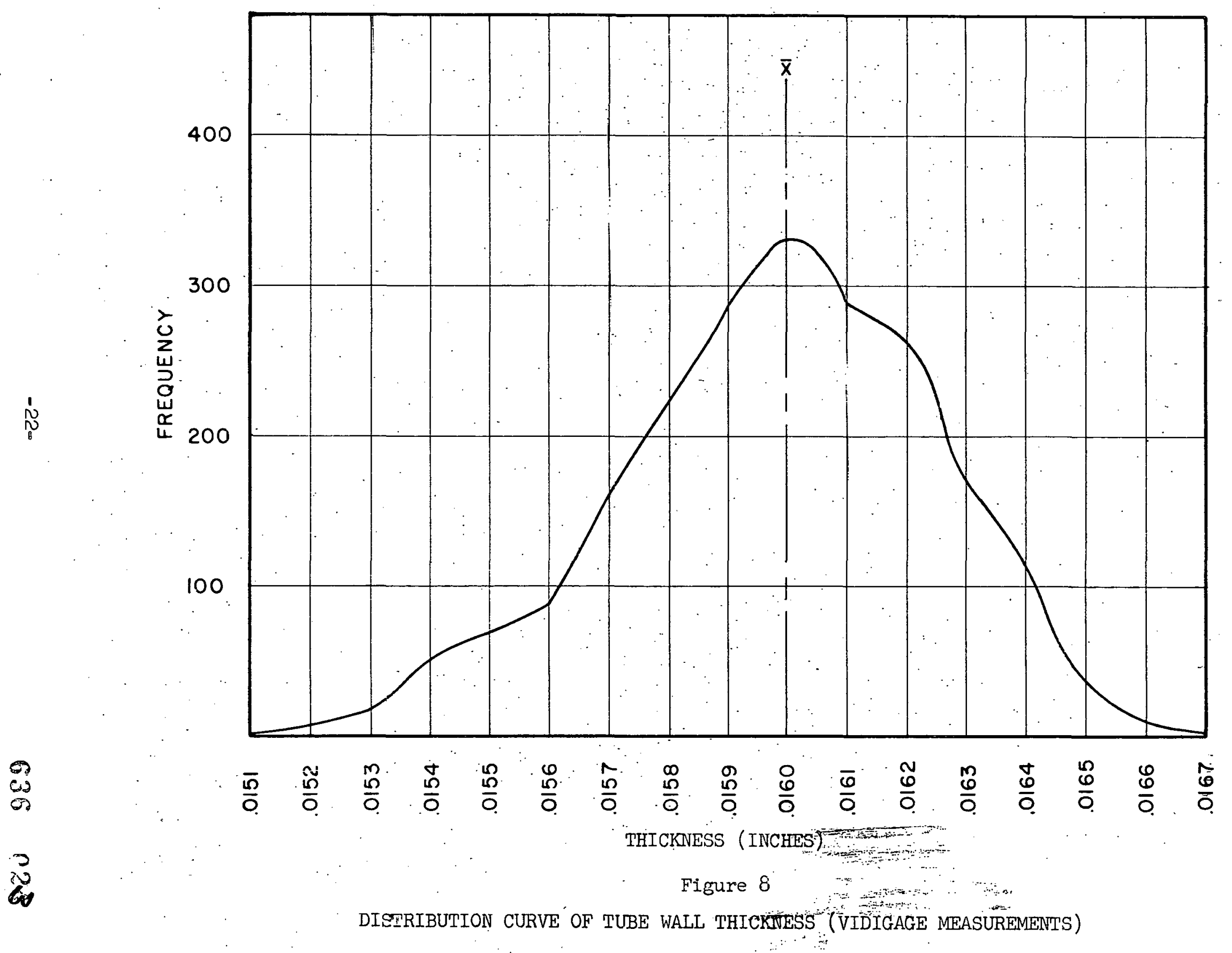




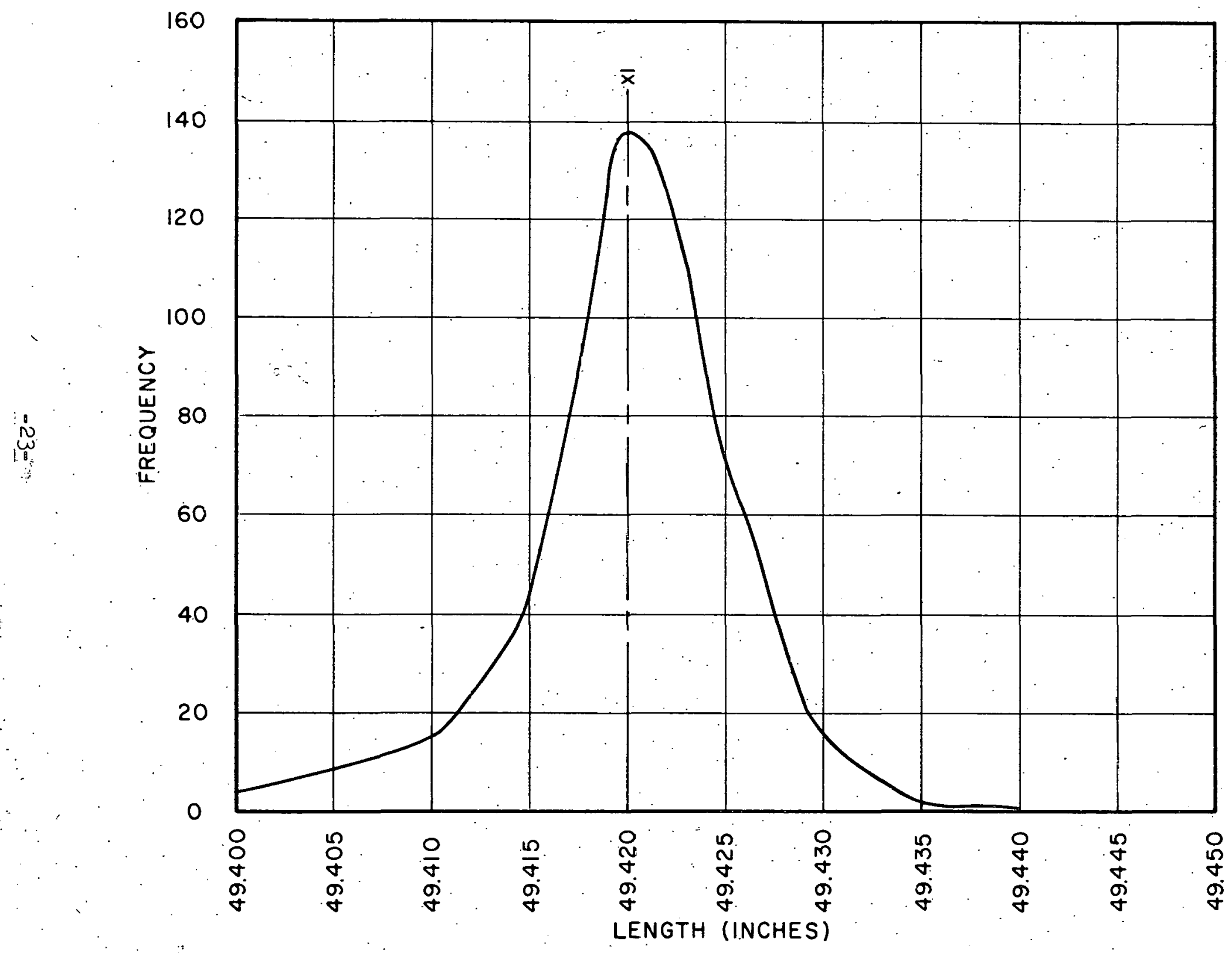

Figure 9

DISTRIBUTIOH CUTWE OF TURE LJNGTH MTAGURTAENTS. 

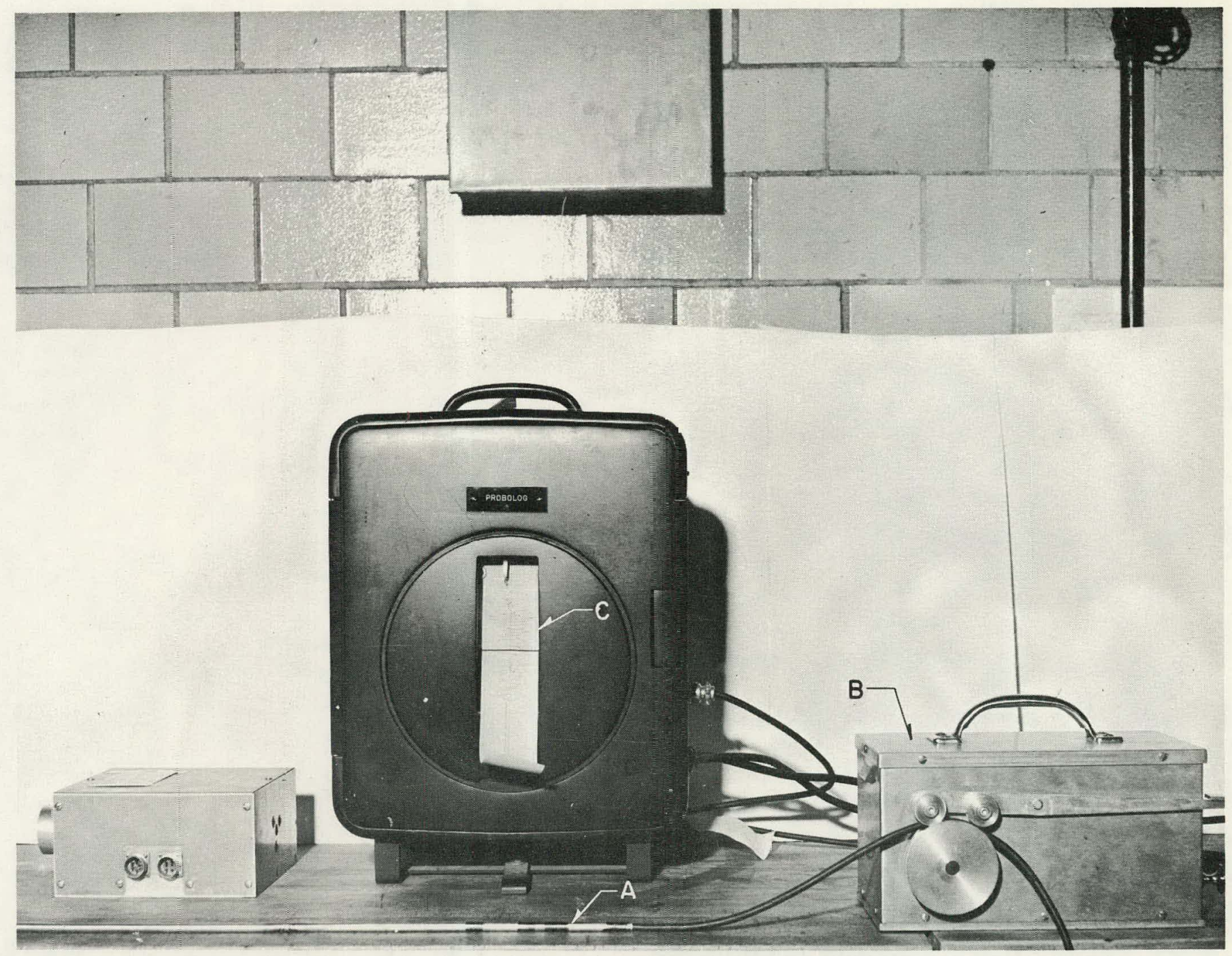

Figure 10

TESTING TUBE INTEGRITY

CRX tube being tested for integrity using the Eddy Current Method. The probe is -nserted into tube (A). The puller (B) moves the proke through the inside of the tube at a constant speed. Any discontinuity present will be recorded on the strip chart (c). 
this test quantitative. Figure 11 (a) represents the trace recording showing a typical indication and Figure $11(\mathrm{~b})$ is an enlargement of a partial area of the sectioned tube.

An investigation was conducted to determine if the as-received tubes were clean enough to be used in the manufacture of the CRX rods. The macroscopic neutron cross section absorption of foreign matter discovered should total less than the equivalent of 0.001 grams of natural boron (approximately one percent of that due to the steel itself) to be acceptable.

A comparison was made of foreign material on tubes cleaned using the procedure given in Table IX and material on the interior of the asreceived tubes by spectrographic anaiysis. Table VIII is the calculation of the total macroscopic absorption cross-section of the major foreign cations on the interior wall of the as-received tubes based on the spectrochemical analysis.

\section{TABLE VIII}

Macroscopic Cross Section Calculations of Foreign Matter on As-Received CRX Tubes

\begin{tabular}{|l|r|}
\hline Cation & $\begin{array}{c}\text { Macroscopic Absorption } \\
\text { Cross Section } \mathrm{cm}^{2} / \mathrm{cm}^{3}\end{array}$ \\
\hline Fe & $3.50 \times 10^{-5}$ \\
B & $4.30 \times 10^{-5}$ \\
Cu & $.03 \times 10^{-5}$ \\
Ag & $1.40 \times 10^{-5}$ \\
Ni & $.05 \times 10^{-5}$ \\
Si & $2.40 \times 10^{-5}$ \\
Ca & $.01 \times 10^{-5}$ \\
& $.05 \times 10^{-5}$ \\
\hline Total & $11.74 \times 10^{-5}$ \\
\hline
\end{tabular}

The total macroscopic cross section of $0.00012 \mathrm{~cm}^{2} / \mathrm{cm}^{3}$ is less than $0.1 \%$ of the boron cross section in the stainless steel $\left(0.0003 \mathrm{~cm}^{2} / \mathrm{cm}^{3}\right)$. The as-received tubes could be used for the fabrication of CRX fuel rods without a cleaning step.

Table $\mathrm{X}$ is the spectrochemical report sheet for the analysis of foreign matter extracted from the tubes.

Table XI is the spectrochemical report sheet on the analysis of the detergent used to clean the specimens. 


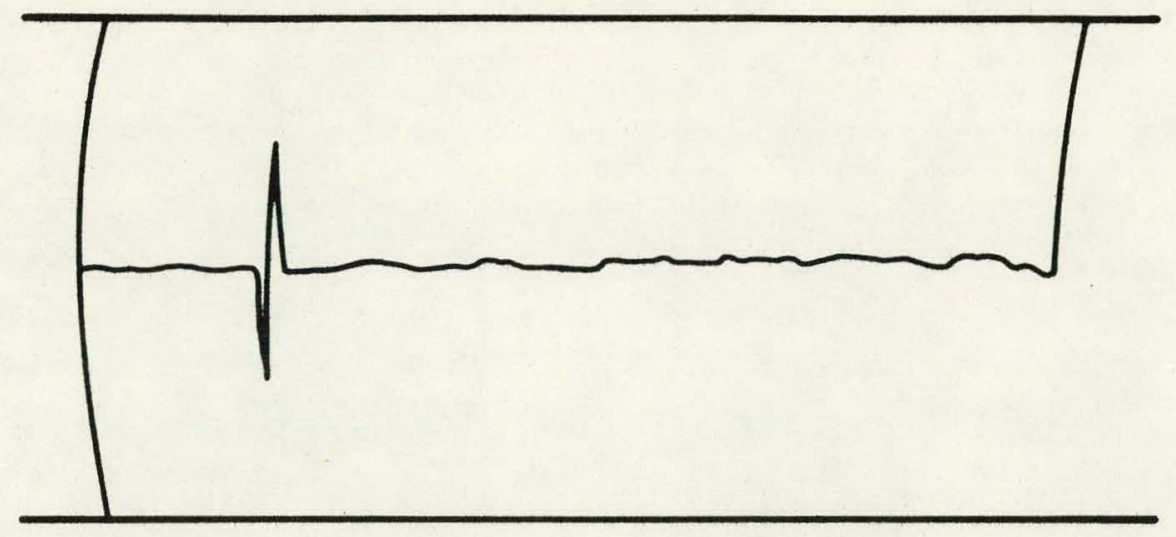

Figure 11

TYPTCAL DFFFCT FOIND RY FIDPY CIIRRENT TFEST

A typical eddy current trace recording (top) of a discontinuity (the "pip" or deviation from trace level) found in a CRX tube. An enlargement of a partial area of the discontinuity is shown in the bottom picture. 


\section{TABLE IX}

\section{Cleaning Procedure for CRX Tubes}

1. Wash the tube in a hot detergent solution (Lever DW 300). $1 / 7$ oz./ 1 gal.

2. Rinse in cold tap water.

3. Wash in a $50-50$ (by volume) methanol and demineralized water solution. " " :

4. Dry in a forced warm afr atmosphere. 
TABLE X

Analysis of Foreign Material on Tubes

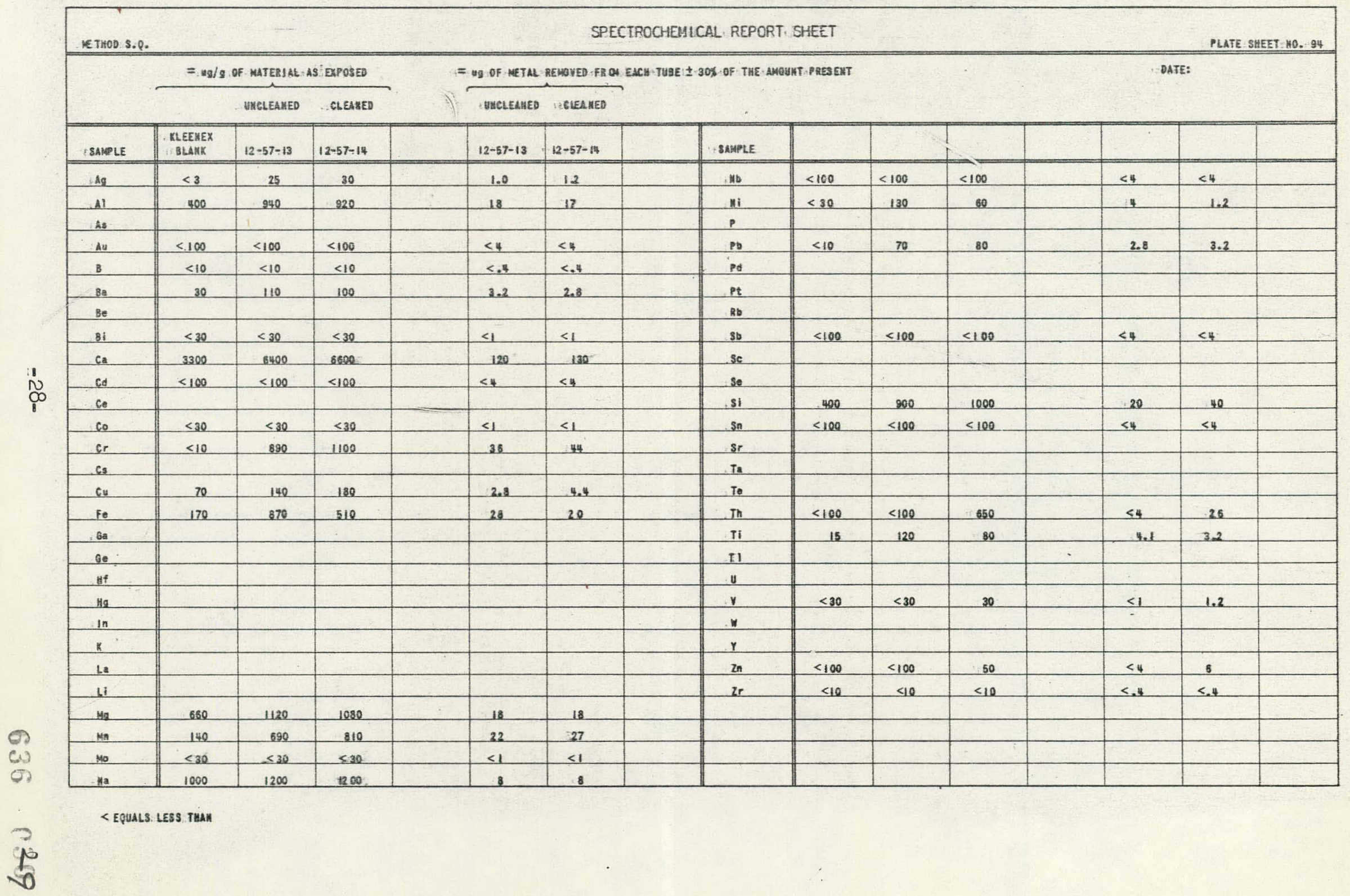


TABLE XI

Analysis of Detergent

SPECTROCHEMICAL REPORT SHEET

METHOO S.O.

RESULTS ARE $I$ IN PPW \pm 6OS OK THE BASIS OF THE ORIG IMAL SAYPLE BY WEIGHT

PLATE SHEET H0. 86

OATE: $11-19-57$

กิ

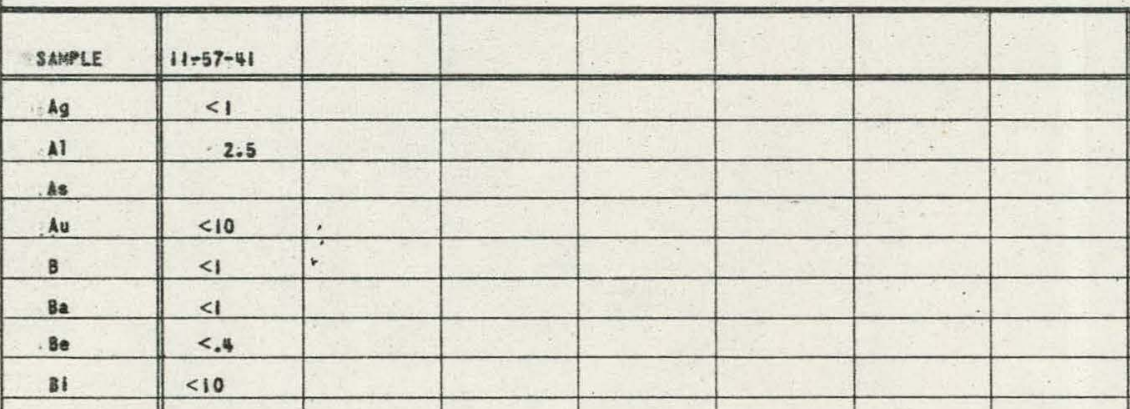

Cu

\begin{tabular}{|l|l|}
\hline fe \\
\hline Ga & \\
\hline
\end{tabular}

\begin{tabular}{|l|l}
\hline Ge \\
\hline iff \\
\hline
\end{tabular}

\begin{tabular}{|c||c|}
\hline Hf & $<40$ \\
\hline Hs & \\
\hline in & $<40$ \\
\hline
\end{tabular}

\begin{tabular}{|c|c|}
\hline In & $<40$ \\
\hline$X$ & \\
\hline$L 2$ & \\
\hline$L i$ & \\
\hline$H Q$ & 9 \\
\hline$H_{n}$ & $<.7$ \\
\hline$H_{0}$ & $<.4$ \\
\hline$H_{2}$ & $<.25$ \\
\hline
\end{tabular}
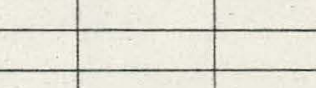

\begin{tabular}{|l|l|l|l}
\hline & & \\
\hline & & \\
\hline
\end{tabular}




\section{B. End Plugs}

The majority (5305 total) of fuel rods were Type A (W Dwg. No. 414C212, Figure 12). Special rods (204 in number) were made for Type $E$ (W Dwg. No. 414C485, Figure 13); Type F (W Dwg. No. 414C480, Figure 14); fourtube fuel assembly (W Dwg. No. 414c280, Figure 15) and cross fuel bundle (W Dwg. No. 548D750, Figure 16).

Three species of end plugs were used to make Type A fuel rods, i.e., lead ends, and two (differing in length) for the handling end. The end plugs were fabricated from 6,400 feet of colddrawn annealed 304 stainless steel rod that had been centerless ground to $.3440-.3450$. The average diameter of the ground rod was $0.3447^{\prime \prime}$.

Samples of rod were turned down on a lathe. No laps, cracks or seams were found. A summary of inspection data for Type A end plugs follows:

\section{TABLE XII}

Inspection Data Summary

Type A Fuel Rod End Plugs (long)

\begin{tabular}{|l|c|c|c|}
\hline Variable & Length (in.) & Weight (gm) & $\begin{array}{c}\text { Tube Insert } \\
\text { Diameter (in.) }\end{array}$ \\
\hline Maximum & 5.756 & 64.58 & 0.3090 \\
Minimum & 5.740 & 64.22 & 0.3080 \\
Range & .007 & 0.36 & 0.0010 \\
Average & 5.751 & 64.41 & 0.3085 \\
$\sigma$ & .0003 & 0.09 & .0002 \\
Sample Size & 2896 & 143 & 2889 \\
& & & "Wild" 7 \\
\hline
\end{tabular}

TABLE XIII

Inspection Data Sumary

Type A Fuel Rod End Plue (shnrt)

\begin{tabular}{|l|c|c|c|}
\hline Variable & Length (in.) & Weight (gm) & $\begin{array}{c}\text { Tube Insert } \\
\text { Diameter (in.) }\end{array}$ \\
\hline Maximum & 6.2505 & 70.645 & 0.3097 \\
Minimum & 6.2475 & 70.255 & 0.3067 \\
Range & .0030 & 0.390 & 0.0030 \\
Average & 6.2487 & 70.4288 & 0.3086 \\
$\sigma$ & .0006 & 0.088 & .00015 \\
Sarnile Size & 150 & 160 & 2952 \\
\hline
\end{tabular}




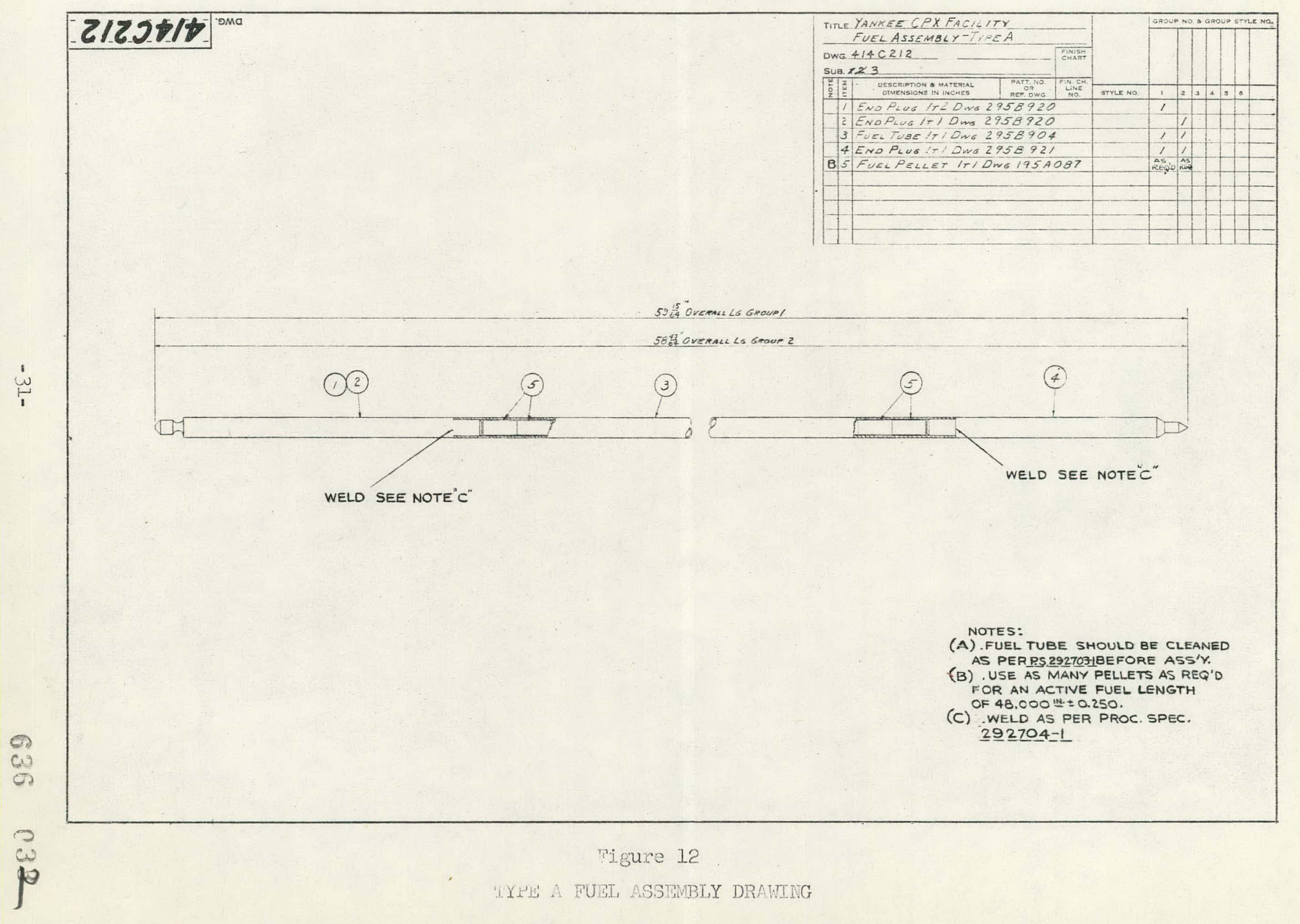




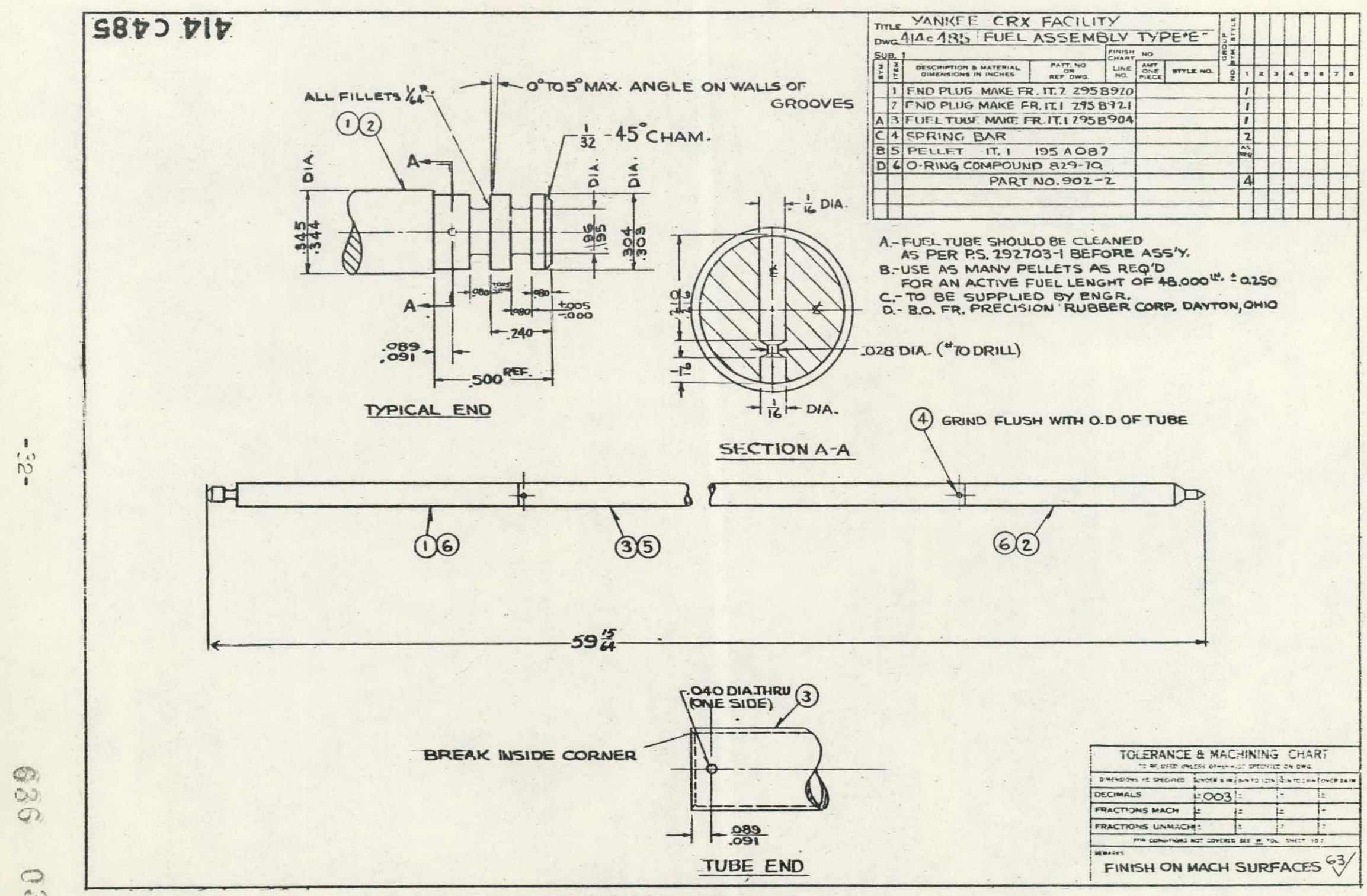

Figure 13

TYPE E FUEL ASSEMBLY DRAWING 


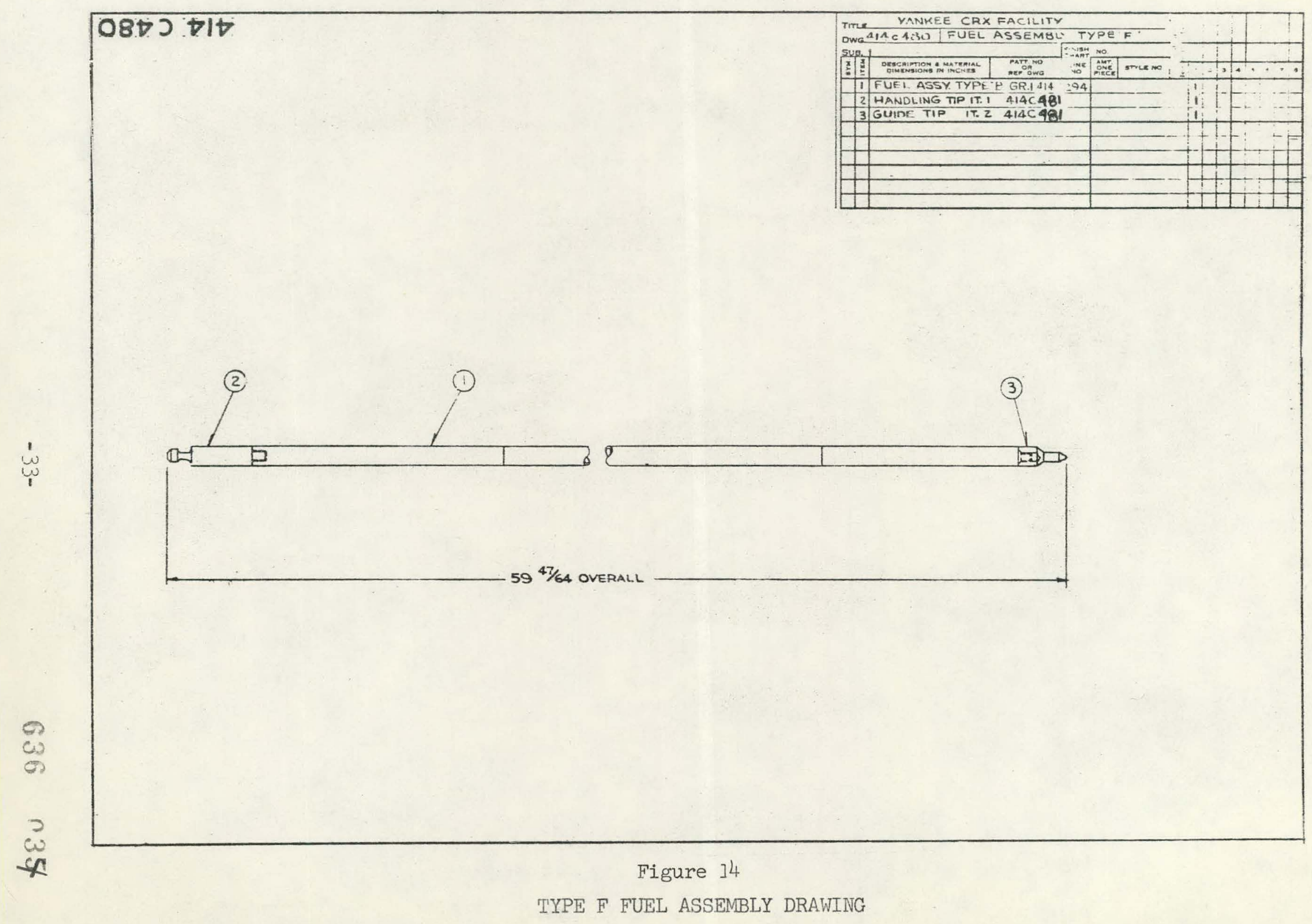




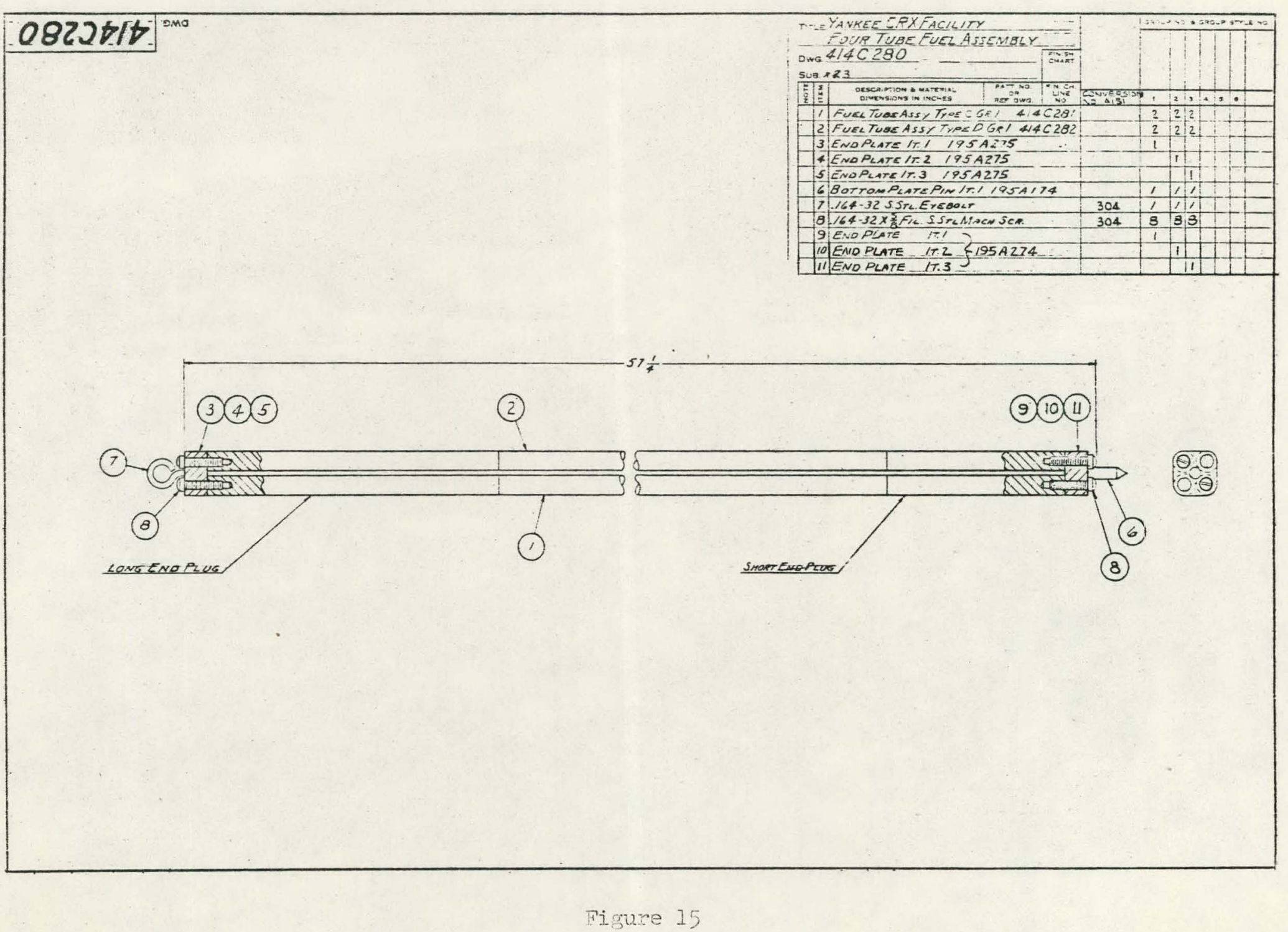

FOUR-TUBE FUEL ASSTMBLY DRAWTNG 


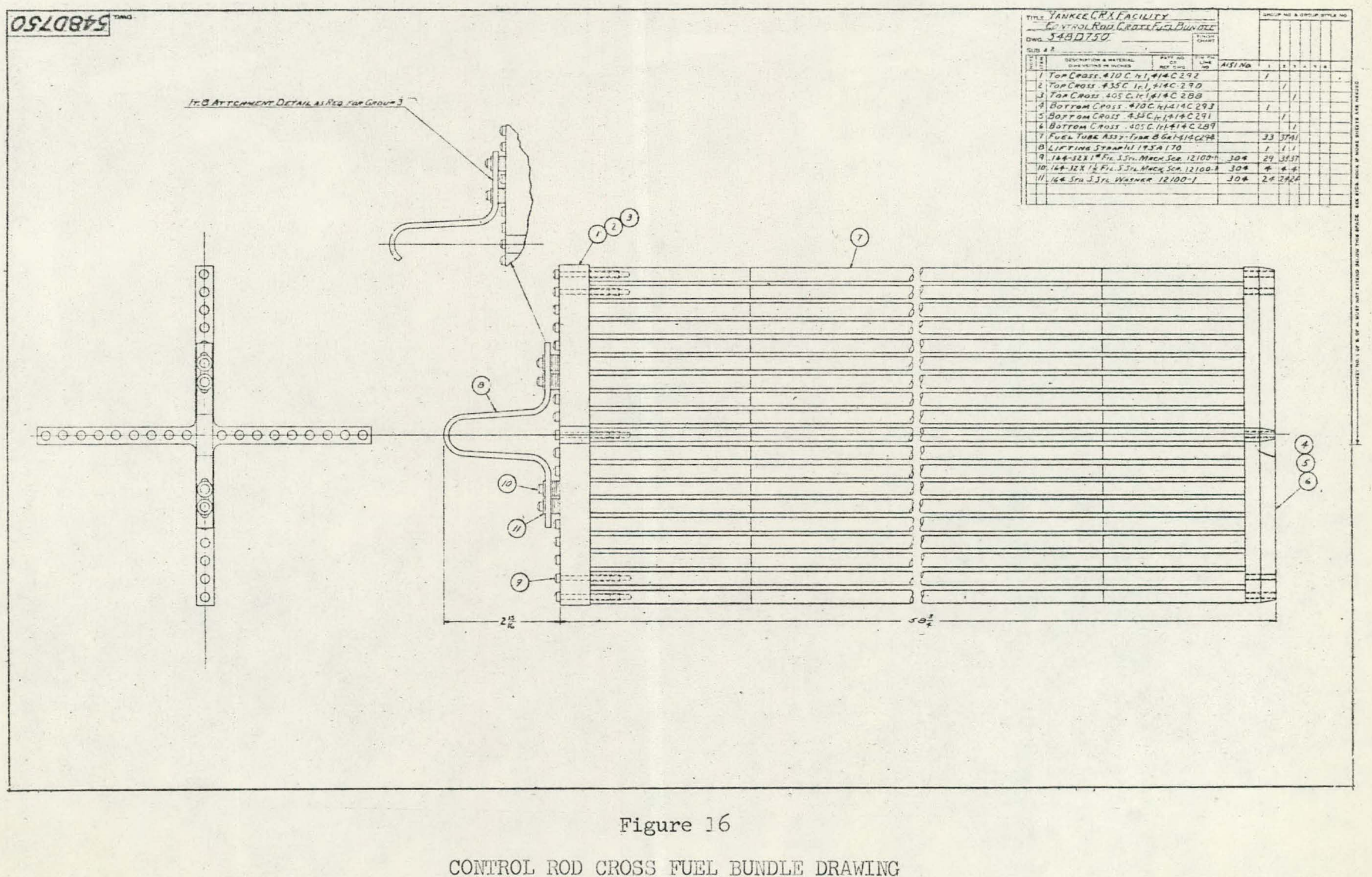




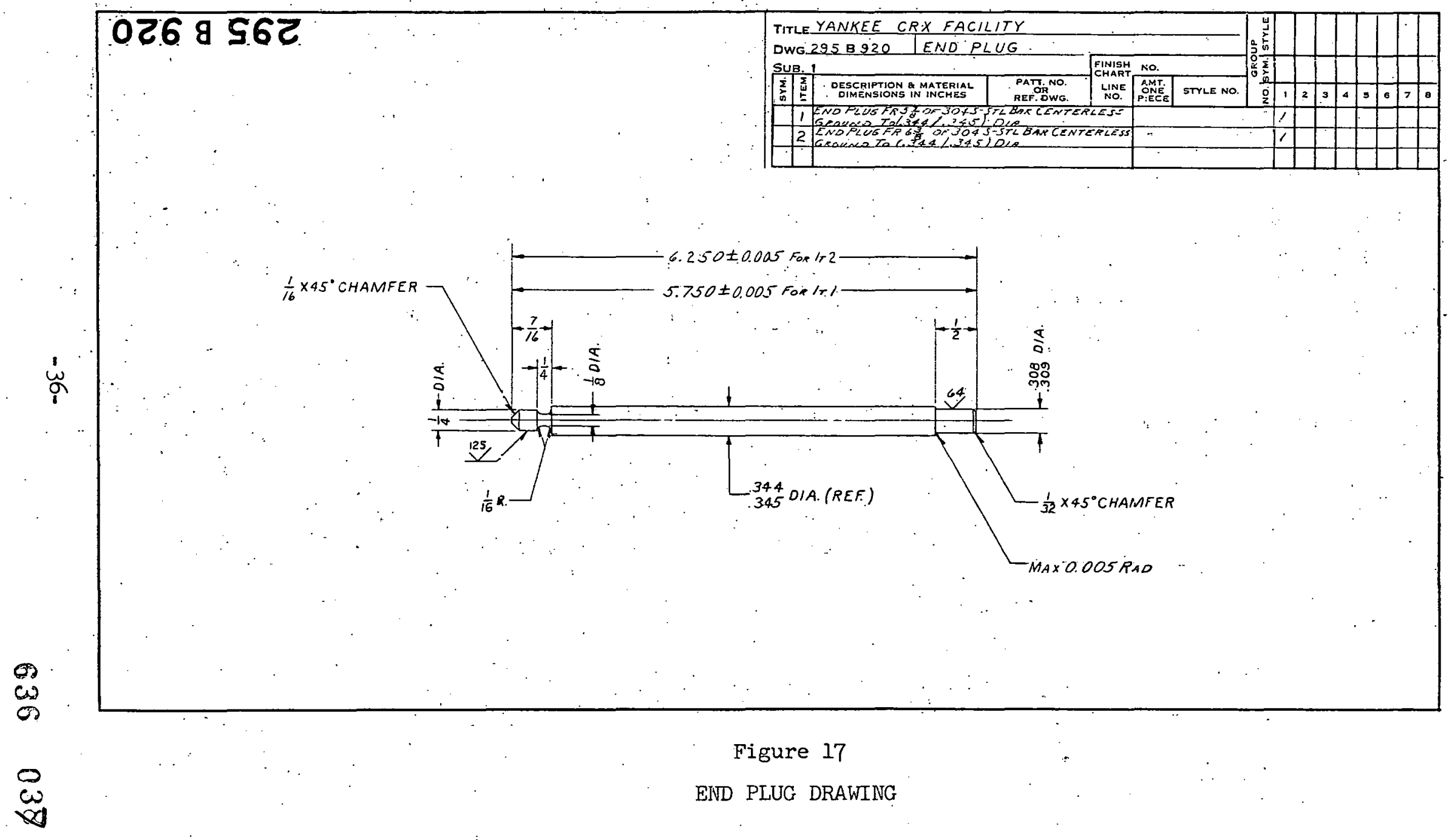




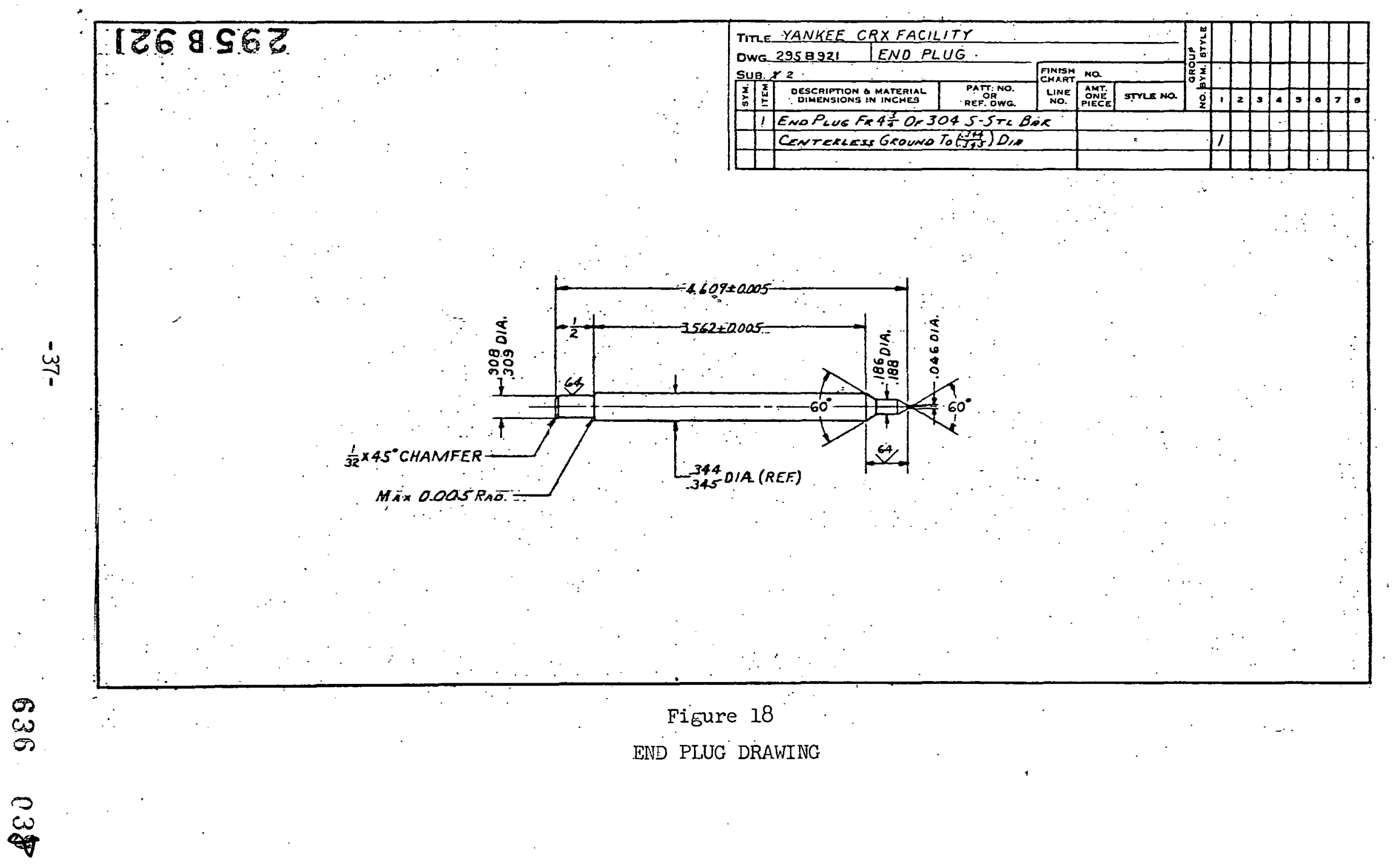




\begin{tabular}{|l|c|c|c|c|}
\hline Variable & Length (in.) & Weight (gm) & $\begin{array}{c}\text { Tube Insert } \\
\text { Diameter (in.) }\end{array}$ & $\begin{array}{c}\text { Tip End } \\
\text { Diameter (in.) }\end{array}$ \\
\hline Maximum & 4.6085 & 50.225 & 0.30945 & 0.1881 \\
Minimum & 4.6025 & 49.865 & 0.30785 & 0.0161 \\
Range & .0060 & 0.360 & 0.00160 & 0.002 \\
Average & 4.6067 & 30.0356 & 0.30869 & 0.1868 \\
& 0.0004 & .0677 & .0007 & 0.0009 \\
Sample & 3192 & 300 & 2895 & 3153 \\
Size & & & & \\
\hline
\end{tabular}

In Figure 19 the frequency distribution curves for the tube insert diameters for the three end plugs are compared.

\section{Uranium Dioxide Pellet Inspection}

The lack of production information on a batch basis of pellet parameters prompted the selection of a $4 \%$ sample, the recording of data in notebooks, and the determination of densities by the "wet" density method (Table XVIII)。

Within a short period of time (See Table XV) it became evident that the amount of work entailed to procede on the above basis was a hindrance to an efficient production of fuel rods. It was decided, after studying the accumulated data, to reduce the sampling plan to $2 \%$ and use calculated densities as the acceptance standard. Wet densities were run in doubtful cases.

At a later date and after studying the inspection results it. was decided to further increase the quantity of pellets released to production by: 1. decreasing the sample size to $1 \%$, 2. constructing a nomograph for determining densities, 3. introducing a single entry card system for recording data. Upon introduction of these measures, no delays occurred which were caused by waiting for release of pellets. Figure 20 shows a typical inspection card.

Table XV shows the evolution of the sampling plan finally developed to inspect incoming pellets.

TABLE XV

Evolution of Pellet Sampling Plan

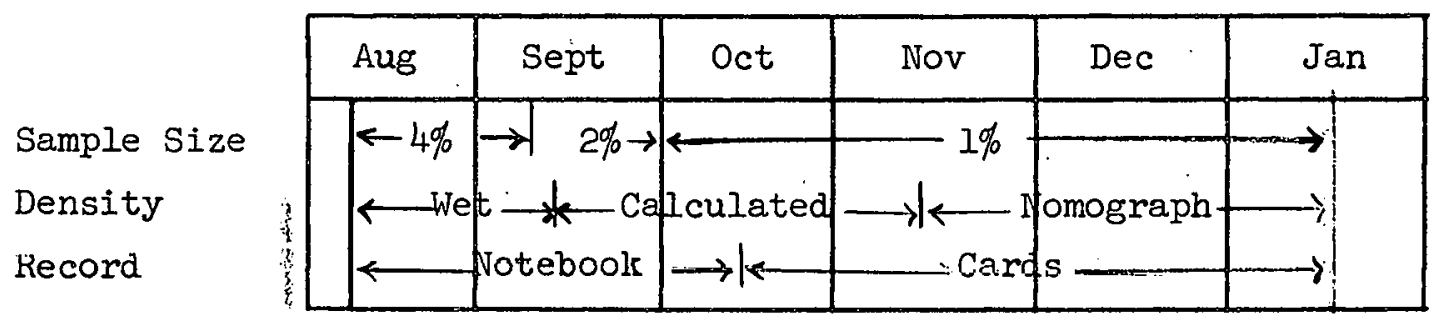




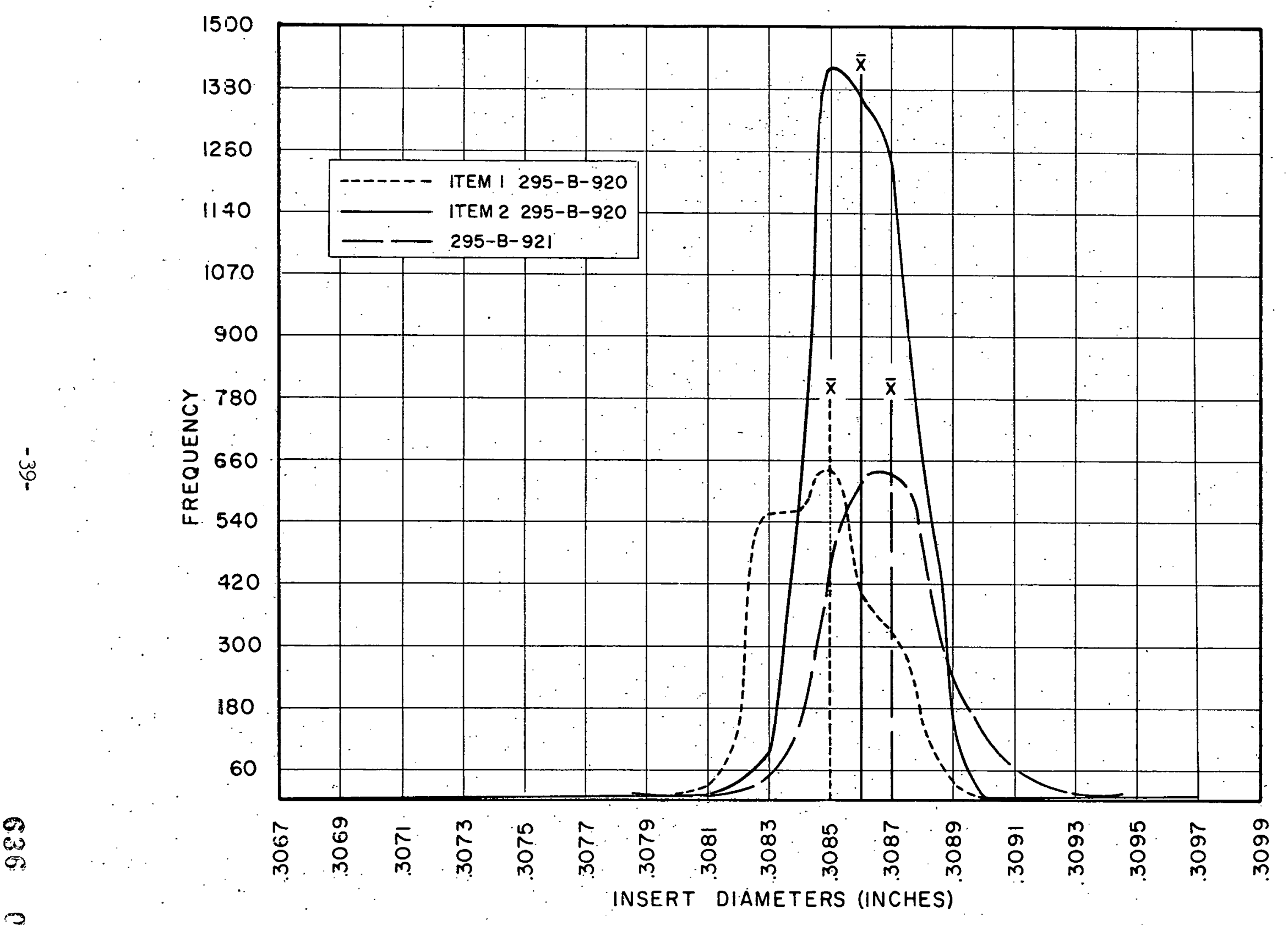

2

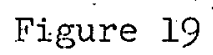

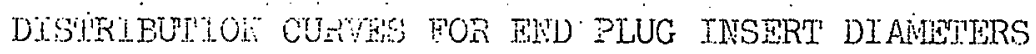




\section{PELLET INSPECTION}

INSPECTOR

SAMPLE SIZE 6 FROM 500

LOT NO. RC.76-6-3

DATE $11 / 8 / 57$

\begin{tabular}{|c|c|c|c|c|}
\hline & HEIGHT & WEIGHT & DIAMETER & DENSITY \\
\hline 1 & .6005 & 7.0378 & .3001 & 92.22 \\
2 & .5982 & 7.0231 & .3001 & 92.40 \\
3 & .5981 & 7.0084 & .2995 & 92.40 \\
4 & .5989 & 7.0283 & .2999 & 92.23 \\
3 & .5958 & 6.9411 & .2996 & 91.78 \\
6 & .5949 & 6.9816 & .2997 & 92.50 \\
AVE. & .5977 & 7.0034 & .2998 & $92.255^{\prime}$ \\
\cline { 2 - 5 } & & & & $92.4187^{2}$ \\
\hline
\end{tabular}

\section{NOMOGRAPH READINGS}

1. AVERAGE NOMOGRAPH READING

2. CALCULATED FROM AVERAGE HEIGHT, WEIGHT, AND DIAMETER

Figure 20

PELTET INSPECTION DATA CARD 
Pellets were sampled and accepted on a batch (one can - approximately 500 pellets) basis. About 1015 batches were received and inspected. The accumulated sample size was 6800 pellets or about $1.5 \%$ of the total quantily of peliets received. Figure '2l is the pellet drawing. Figure 22 shows the measurement oi' lengin aid diameter of pellets.

The pellet inspection data is summarized below:

TABLE XVI

Pellet Inspection Data Summary

\begin{tabular}{|l|c|c|c|}
\hline Variable & Diameter (in.) & Length (in.) & Weight (gm) \\
\hline Maximum & .3005 & .6850 & 7.8500 \\
Minimum & .2993 & .5250 & 6.3500 \\
Range & .0012 & .0267 & 1.500 \\
Average & .3000 & .5989 & 7.0699 \\
$\sigma$ & .0002 & .0034 & 0.1281 \\
Sample Size & 6894 & 6783 & 6786 \\
& "Wild"10 & & "Wild"15 \\
\hline
\end{tabular}

Figures 23,24 , and 25 are distribution curves for the diameters, lengths, and weights, respectively.

Three methods of determining densities for production control were studied in conjunction with the program to make the pellet inspection program more efficlent. Nomograph readings were compared to densities as calculated from data taken from the same samples.

: TABLE XVII

Nomograph VS Calculated Density Data

\begin{tabular}{|l|c|c|}
\hline Method & Nomograph & Calculated \\
\hline Maximum & 95.25 & 95.25 \\
Minimum & 90.75 & 90.25 \\
Range & 4.50 & 5.00 \\
Average & 92.97 & 93.08 \\
$\sigma$ & 1.03 & 0.83 \\
Sample Size & 408 & 408 \\
\hline
\end{tabular}




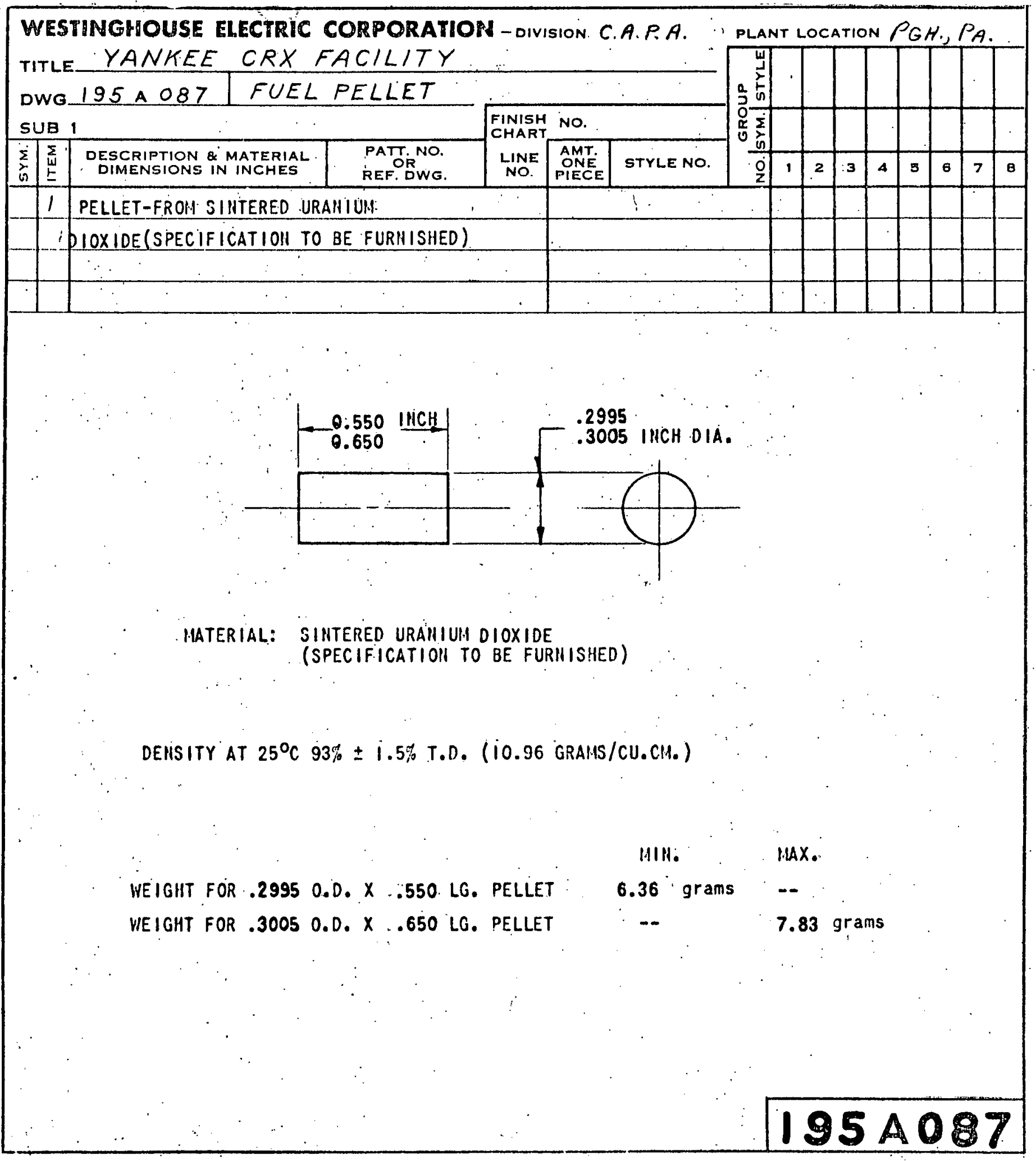

Figure 21

PEI.T.KT! DRAWING 


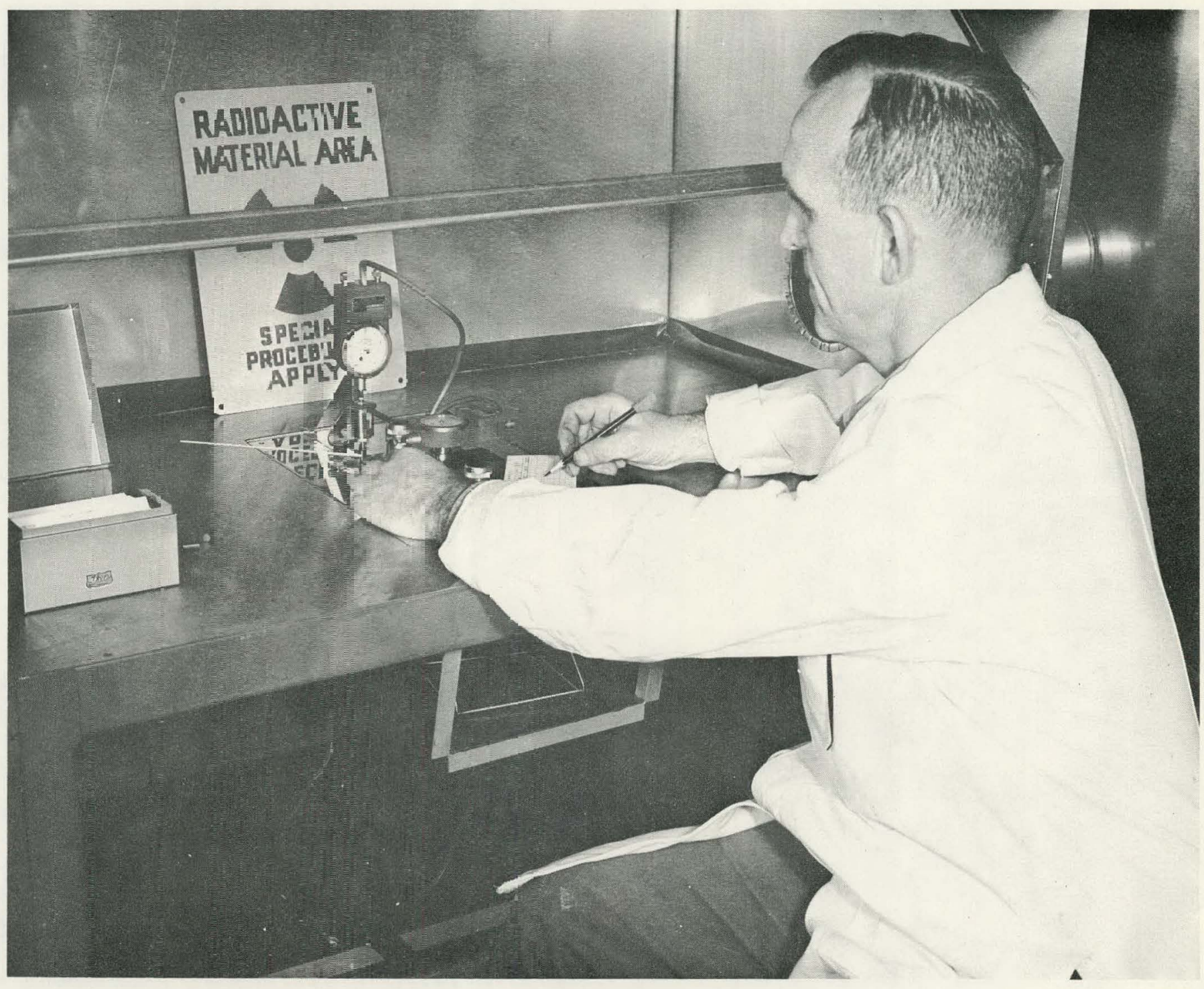

Figure 22

VEAELERMIIT OF PELLET LENGTH AND DIAMETER Tre arror points to a pellet being measured. 


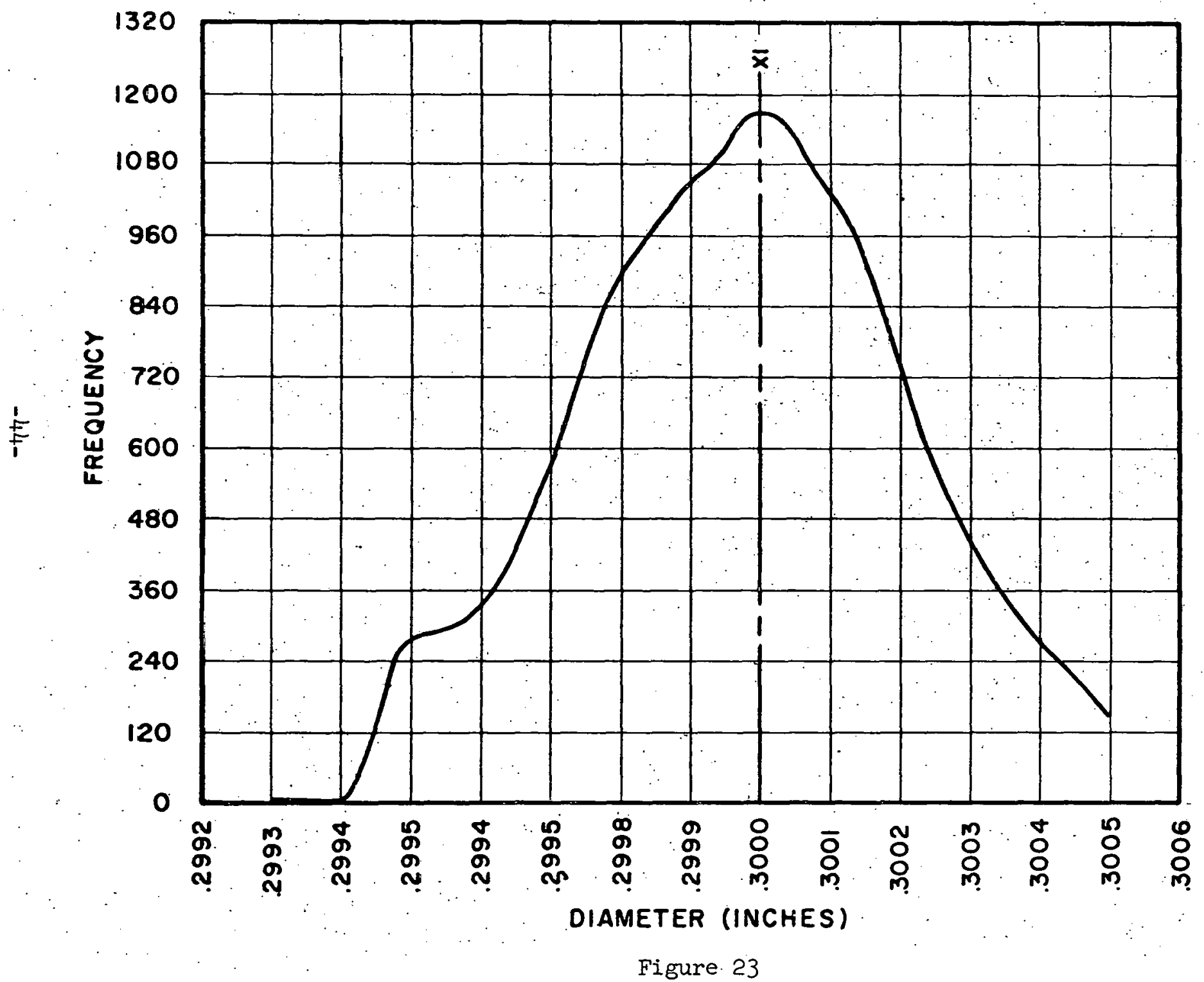

3

DISTRIBUTION CURVE OF PELLET'DIAMETERS 


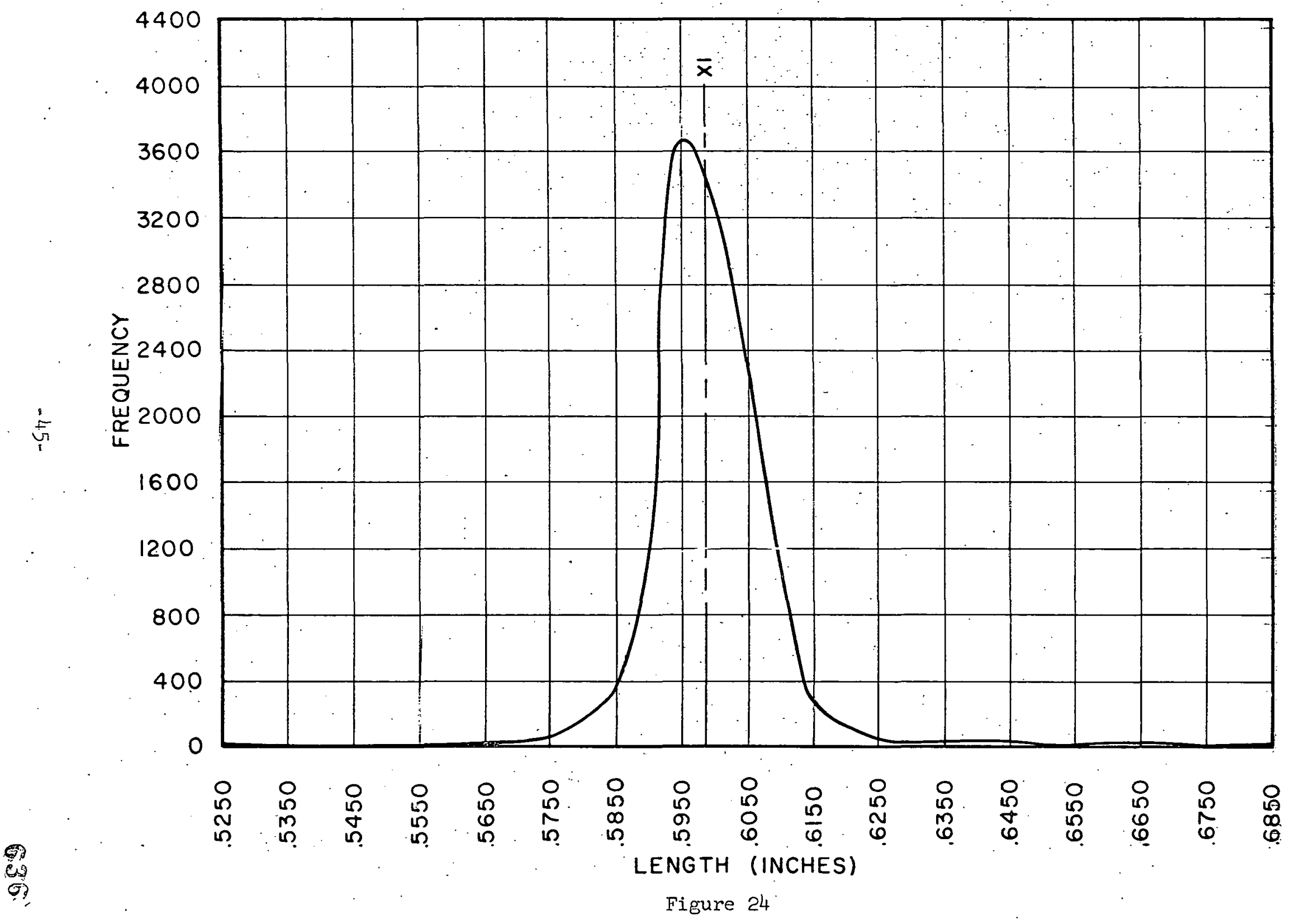

DISTRTBUTION CURVE OF PELLEN LEIVGIHS

急 


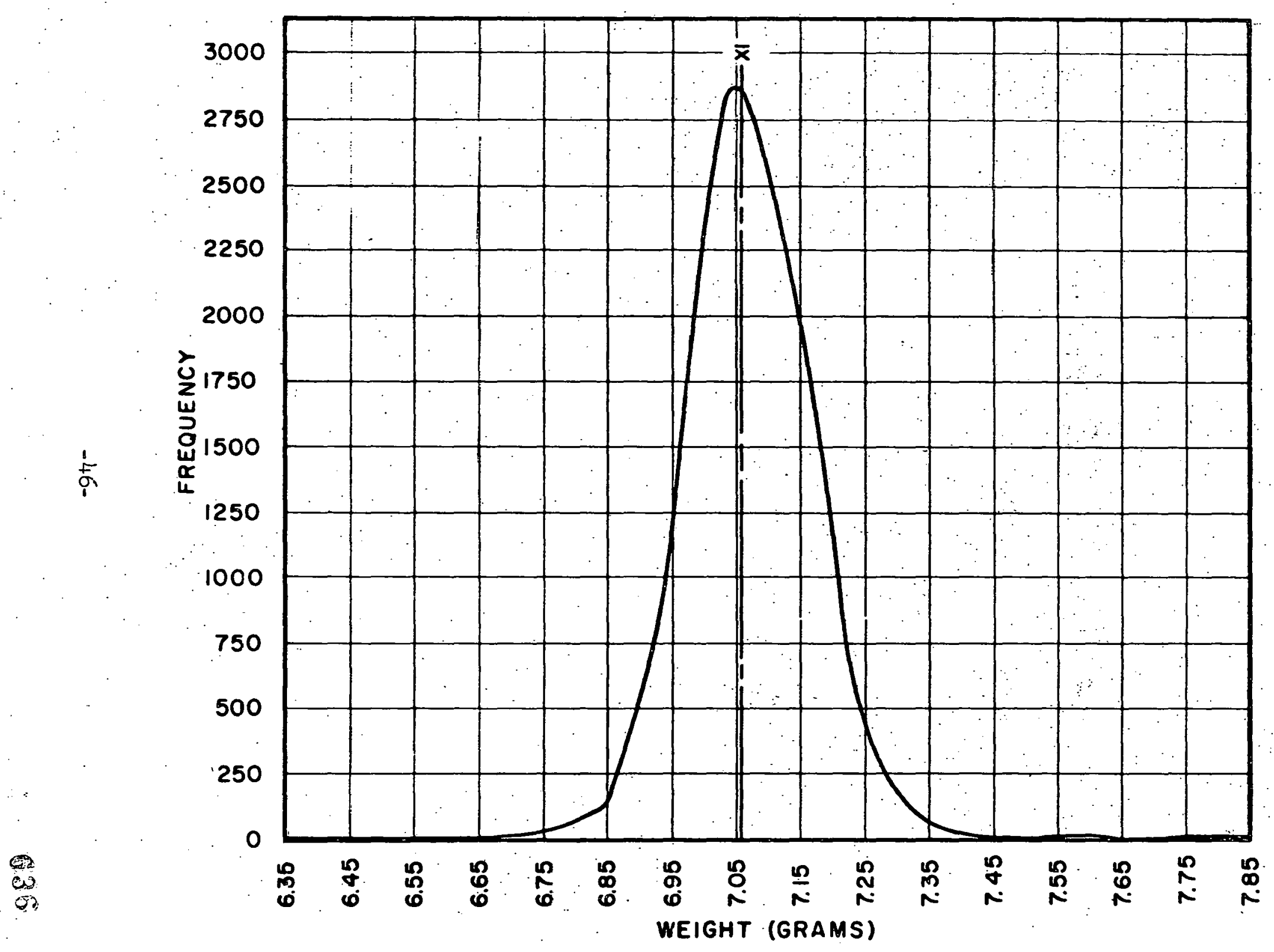

2

DISTRIBUTION CURVE OF PELLET WEIGHTS 
Calculated densities were compared to densities as determined by the "wet" density method (see Table XVIII). Table XIX summarizes these data.

\section{TABLE XIX}

\section{Calculated vs Wet Densities}

\begin{tabular}{|l|c|c|}
\hline Method $\cdots$ & Calculated & Wet \\
\hline Maximum & 95.25 & 94.25 \\
Minimum & 91.25 & 90.75 \\
Range & 4.00 & 4.50 \\
Average & 93.02 & 93.09 \\
$\sigma$ & 1.14 & 1.64 \\
Sample Size & 58 & 58 \\
\hline
\end{tabular}

Figure 27 shows the distribution curves for the pellet densities as determined by three different methods on essentially the same pellet samples.

Table XX is a comparison of analyses made on the different "lots" of pellets.

VI. Manufacture of Fuel Rods

The manufacturing procedure is given in Table XXI. The three main steps are: 1. loading pellets into the tubes, 2 . welding end plugs, and 3. inspection of welds.

\section{A. Tube Loading}

There are five natural variables (in addition to shape deformities, i.e: ovality, out of round of pellets) to be considerea in the fitting of sintered ceramic compacts or pellets into tubes to make fuel rods. These are:

1. Variation in diameter within a pellet.

2. Variation in diameter from pellet to pellet.

3. Variation in inside diameter within a tube."

4. Variation in inside diamëter from tube to tube.

5. Variation due to allowable clearance tolerances.

The limiting design factors are the maximum allowable gap (diameter differences) as determined from heat transfer calculations and the minimum gap that will permit ease of insertion of the pellets in the tube. In order to have $100 \%$ certainty that all pellets would fit in all tubes, a minimum gap of $0.0025^{\prime \prime}$ is necessary. The CRX fuel rod was designed to have a nominal gap of $0.0060^{\prime \prime}$. The maximum and minimum gaps are $0.0085^{\prime \prime}$ and $0.0035^{\prime \prime}$, respectively. 
Procedure for Determining Density of $\mathrm{UO}_{2}$ Pellets

by the Wet Density Method

1. Modify a Stanton balance (Model B) as shown in Figure 26 by replacing the left pan with a suspension wire to hold a basket made. from fine mesh stainless steel screen. Position a platform directly beneath the suspended basket to raise the beaker. of water to a predetermined level.

2. Zero the balance.

3. Select ten pellets randomly from the batch under test and weigh together in the basket in air. Record as weight of pellets and basket in air.

4: Preset the dialed weights to the approximate weight of pellets and basket in water.

5. Raise the beaker of water (containing two drops of wetting agent, Photo-Flo, Eastman Kodak) to the predetermined level.

6. Immediately, start a stop watch and weigh to the nearest 0.0001 gram. Take subsequent readings every fifteen eeconds for three minutes. (12 weights) Extrapolate the weight to zero time by . plotting the twelve points. Record the zero time weight as the weight of pellets and basket in water.

7. Record the temperature of the water.

8. Remove the pellets from the basket and weigh the basket suspended in water. Record the weight of the basket suspended in water.

9. Dry the basket and weigh suspended in air. Record the weight of the basket in air.

10. Calculate the percent of theoretical density by using the following formula:

$$
\frac{W a k 100}{(W a-W w) 10.96}=\% \text { theoretical density }
$$

where, Wa. a weight of pellets and basket in air mlnus the weight of basket in air.

Ww weight of pellets and basket in water minus the weight of basket in water.

$\mathrm{K}=$ the density of water in $\mathrm{g} / \mathrm{cc}$ for the temperature of water at time of determination, corrected for the presence of the wetting agent.

10.96 z the theoretical $100 \%$ density of sintered Uor peliets. 


\section{TABLE XX}

$\mathrm{NO}_{2}$ PELLET ANALYSis

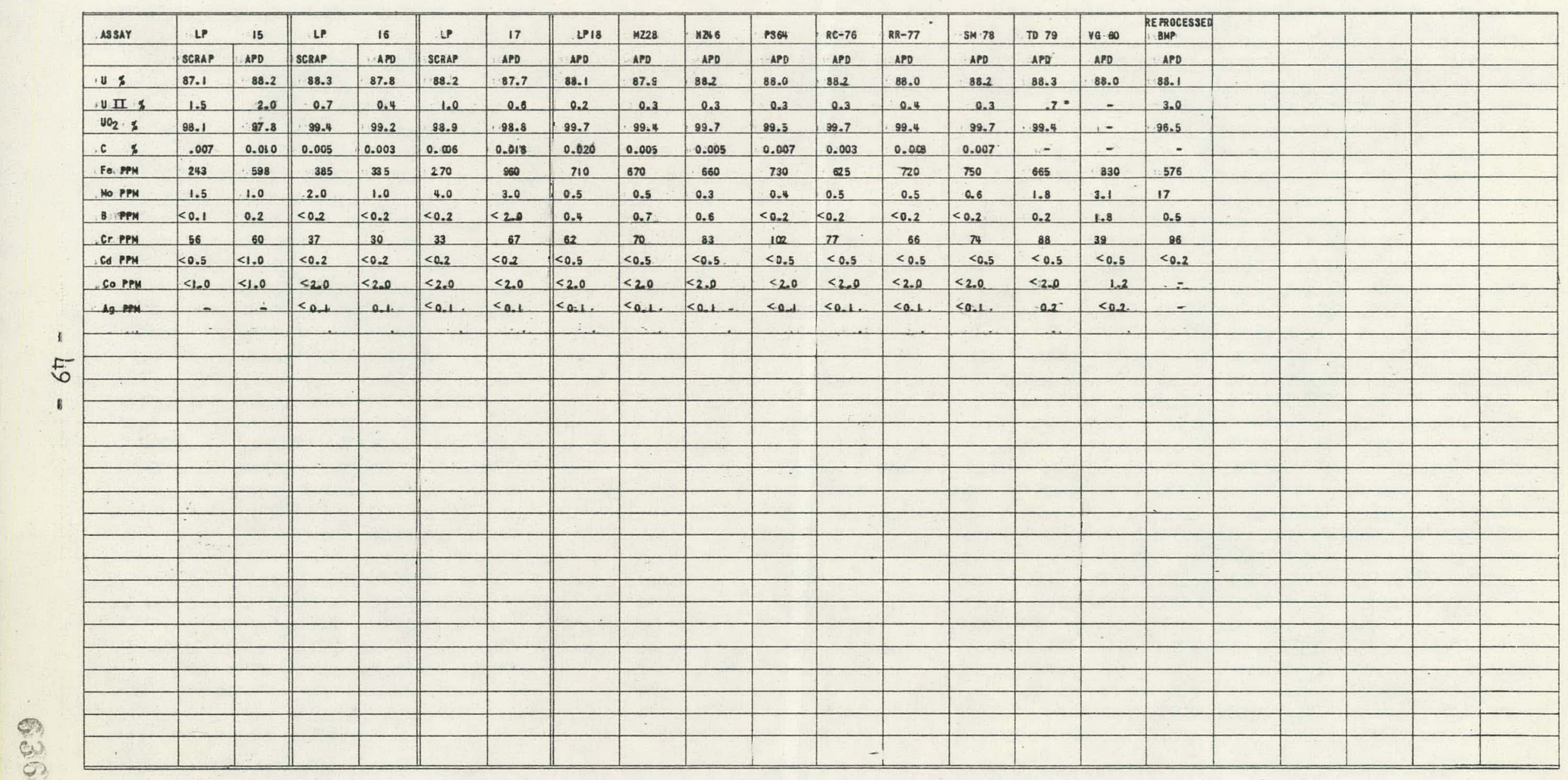




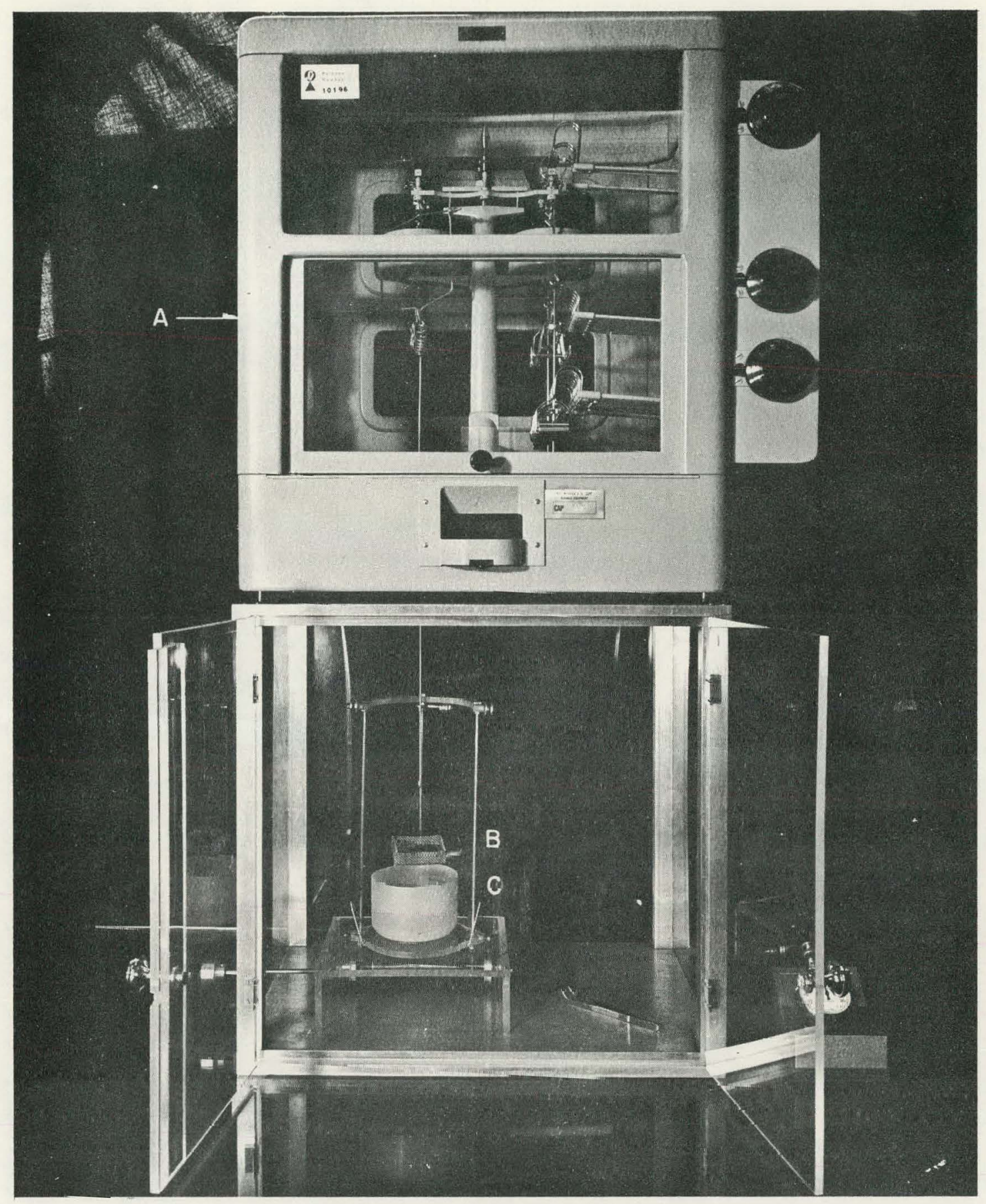

Figure 26

EQUIPMENT FOR DENSITY DETERMINAIIONS

A precision balance (A) is mounted above closed case. The pellets are placed in the basket (B) and weighed. The elevator holding a beaker of water (C) is raised to a predetermined level and the pellct: are weighed suspended in the water. 


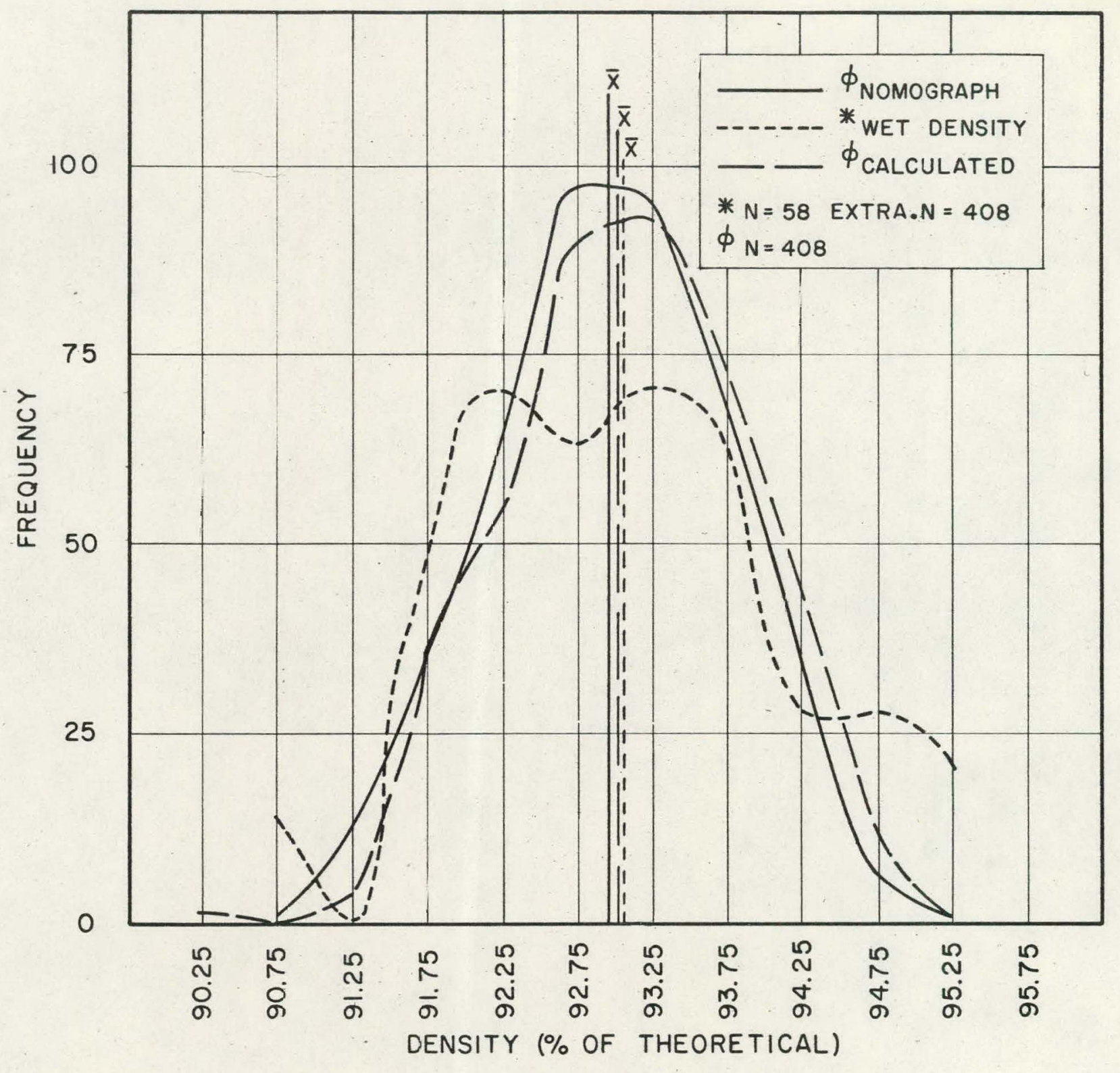

Figure 27

DISTRIBUTION CURVE OF PELLET DENSITIES 
1. Inspect a 5\% tube sample for ID, OD, length, wall thickness and integrity. Record results. Accept or reject.

2. Inspect $5 \%$ sample of various types of end plugs for length and weight. Measure the insert diameters of each end plug. Record results. Accept or reject.

3. Inspect a $1 \%$ sample of each batch (I) of pellets for diameter, length, and welght. Determine density by using a nomograph. If any of the pellets in a batch do not meet specifications, the batch is to be resampled. Record results on single entry. Accept or reject batch.

4. Align approximately 48" of stacked fuel pellets in a "V" block using a Syntron parte aligner.

5. Measure and record the length of the fuel column to the nearest $0.001^{\prime \prime}$ using the gage assembly. Record results on a single entry card.

6. Clean the tube before using.

7. Number individual tube for 1dentity, weigh, empty. Record on same card as in 5 above. Place in tube holder.

8. Insert the pellet column in the fuel tube by pushing on the pellets.

9. Weigh the loaded rod. Record weight on the same card as step 5 above. Calculate weight of fuel and record on card.

Note: These weights are to be used for physics calculations and for uranium accountability purposes.

10. Clean end plugs and wipe out each end of loaded tube with.Q-tip soaked in Acetone.

11. Identify the "handling" end plug $W 414 C 920$ (items 1 and 2 ) by. stenciling number on the withdraw knob portion. Match corresponding numbered end plug and numbered tube. Press both end plugs into tube.

12. Weld end plugs into tubes.

13. Swage pointed end-weld area to reduce area and improve weld.

14. Centerless grind lead end to $.339^{\prime \prime}$ to assure entry into 0.350 " holes in support and spacer plates of the critical experiment tank.

15. V1sually inspect and $\mathrm{X}$-ray welds.

16. Place 50 completed rods in shipping container.

1 A batch is the contents of a pellet shipping container $\cong 500$ pellets or less. 


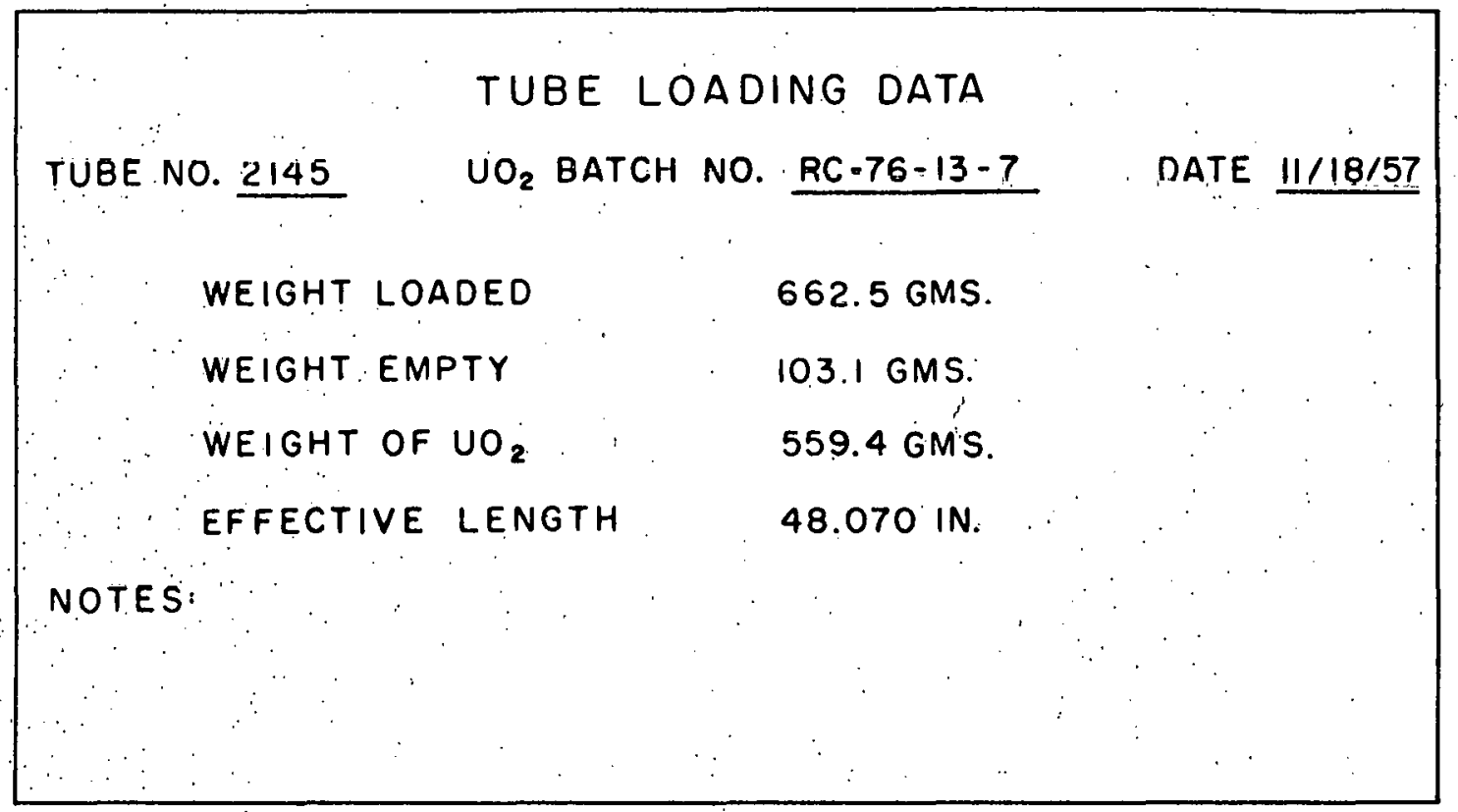

Figure 28

TUBE LOADING DATA CARD 
Several different designs of equipment to be used in the loading of pellets into CRX fuel tubes vere made and tested. An upright tube loader, Figure 29, was made, whose main feature was that a. load could be applied to the piston enabling the losding of a tube with one end plug relded in place. This design was considered for loading $16^{\prime \prime}$ long tubes. A new design specification of a $48^{\prime \prime}$ length made it necessary to find a more feasible method.

Consideration was given to tro types of mechanisms; manual and automatic. The manual pellet loader consisted of a simple " $V$ " block $50^{\prime \prime}$ long which is used to count and manually orient the pellets. Attached to one end. of the " $"$ "' block was a tube holder, offset to make up the tube wall thickness and maintain a straight line for the pellets to travel into the tube.

The automatic device considered consistad of a feeder to orient the pellets and feed them to an escape mechanism. At this point, the pellets are individually pushed down a gravity feed track to a loading mechanism, which in turn loads the pellets into the tubes. The loader incorporated counters, photoelectric lights, and mechanisms. The loading rate was 80 to 100 pellets per minute.

The three reasons for choosing the procedure as given in Table XXI were:

1. The large pellet-to-tube gap (nominal $0.0060^{\prime \prime}$ ).

2. Measurement of the active length of each fuel rod and its weight for nuclear calculations.

\section{Ease of accountability.}

A pellet chipping study showed that a loss of less than $0.5 \%$ of $\mathrm{UO}_{2}$ would be generated if a syntron parts feeder was used. Scrap actually generated plus the unaccountable loss totaled $0.54 \%$.

In the production of the CRX fuel rods, the pellets are aligned in a vibratory device, fed down a chute, and stacked in a " $V$ " block. "The " $V$ " block is calibrated to receive a nominal length of 48 " of stacked pellets. A gage assembly, calibrated with a standard rod is used to measure the length of the fuel column.

A pre-weighed tube is placed and clamped in the tube holder. The " $V$ " block containing the measured column of pellets is lined up with the clamped tube. The pellets are inserted in the tube by pushing on the coluumn.

The loaded tube is veighed. The length measurement and the tube weights are recorded on an inspection card (Figure 28) and the weight of the fuel in the rod is calculated. Figures 30 and 31 show the equipment used for the loading operation. 


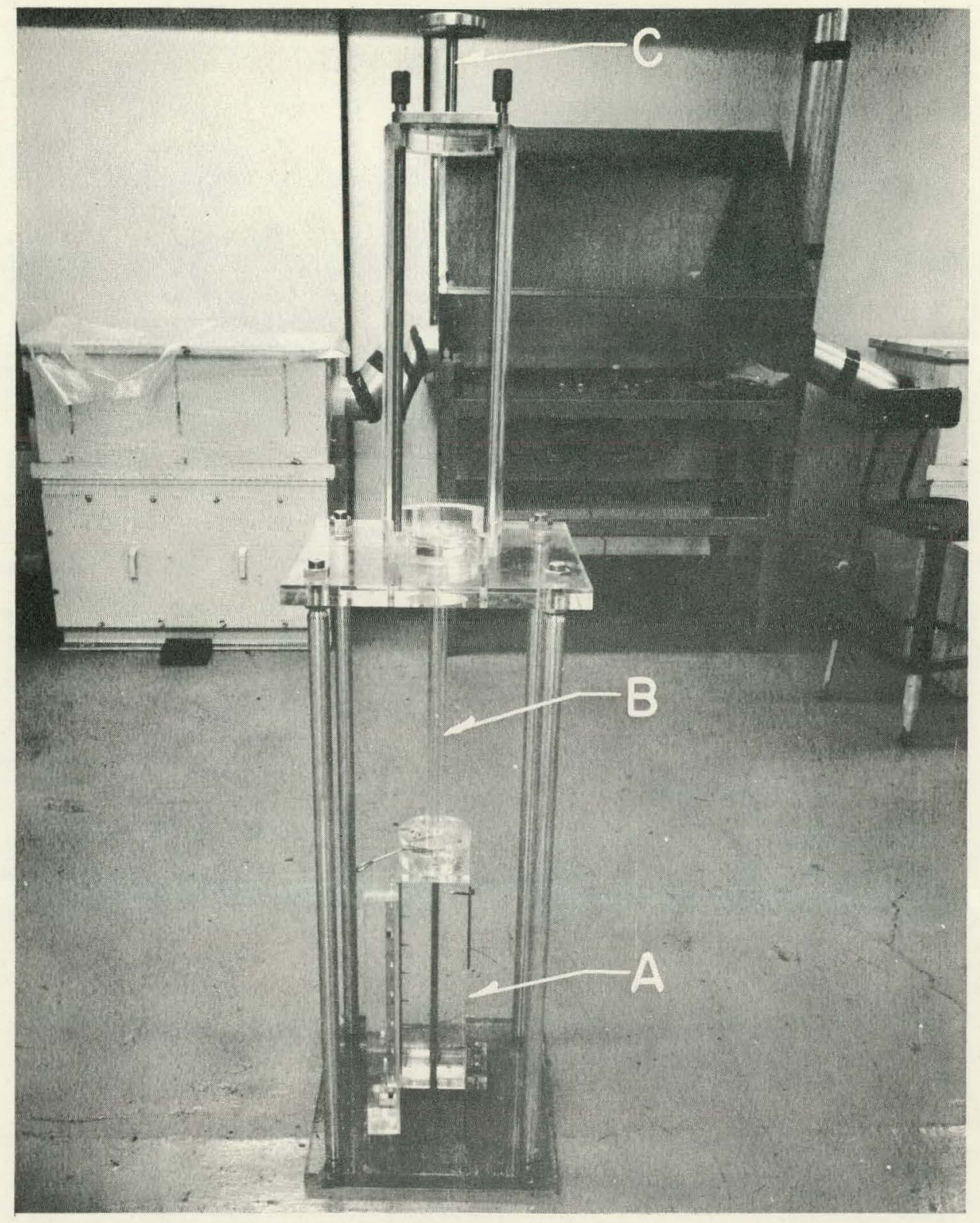

Figure 29

\section{UPRIGHT PELIET LOADER}

The upright type pellet loader considered for the manufacture of CRX rods. The tube with one end plug welded in place is secured in holder (A). Pellets are fed from the channeling tube (B). Force needed to insert pellets into the tube is applied by piston (C). This device proved impractical for the CRX fuel rods. 


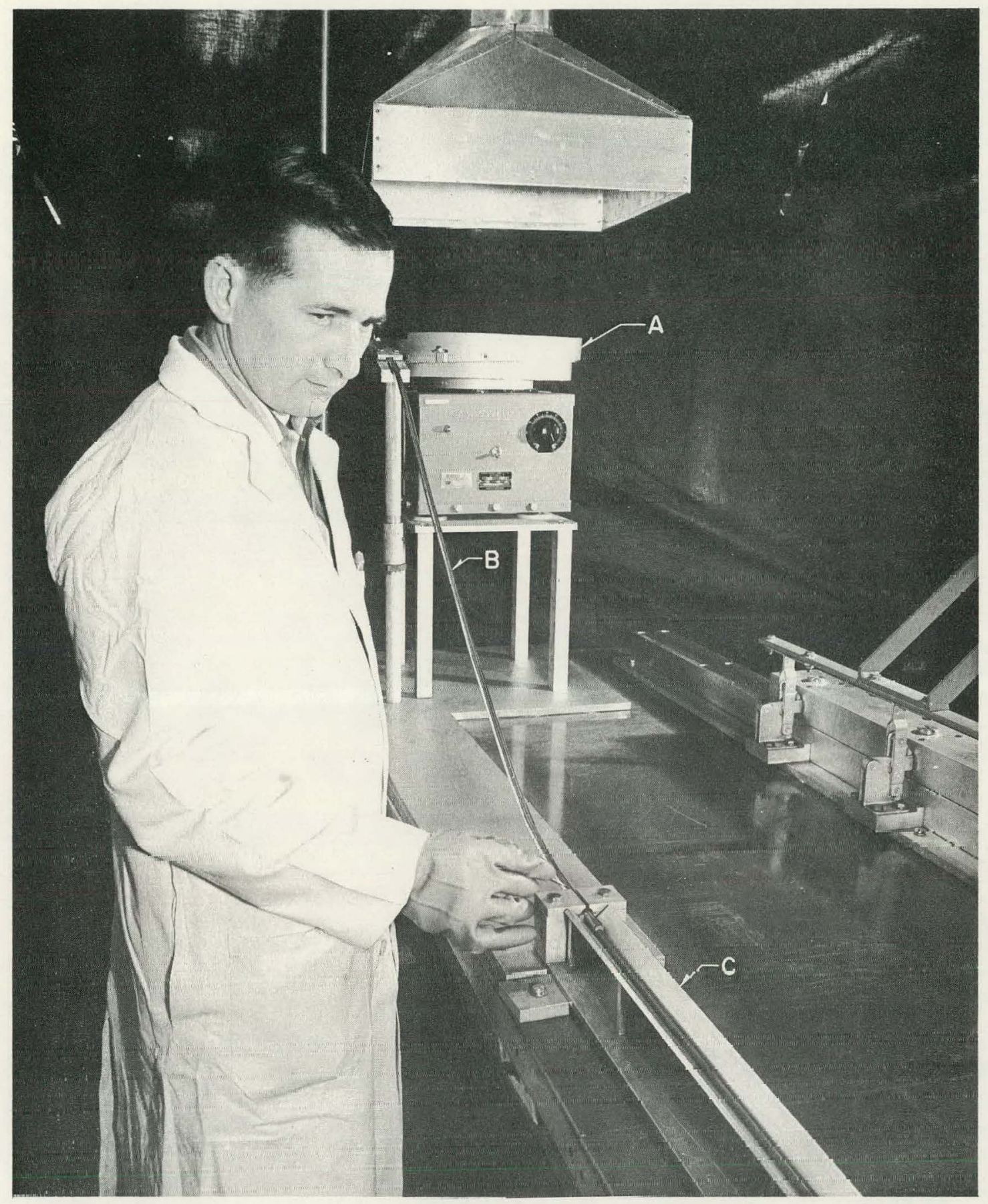

Figure 30

PELLET ALIGNMENI EQUIPMENT

Pellets are aligned for insertion into tubes.

Pellet.s are dumped into a vibratory parts aligner.

(A) and fed down chute (B) into a "V" block (C).

The nominal length of $48^{\prime \prime}$ is inscribed on the " $\mathrm{V}$ "

block to insure the correct number of pellets. 


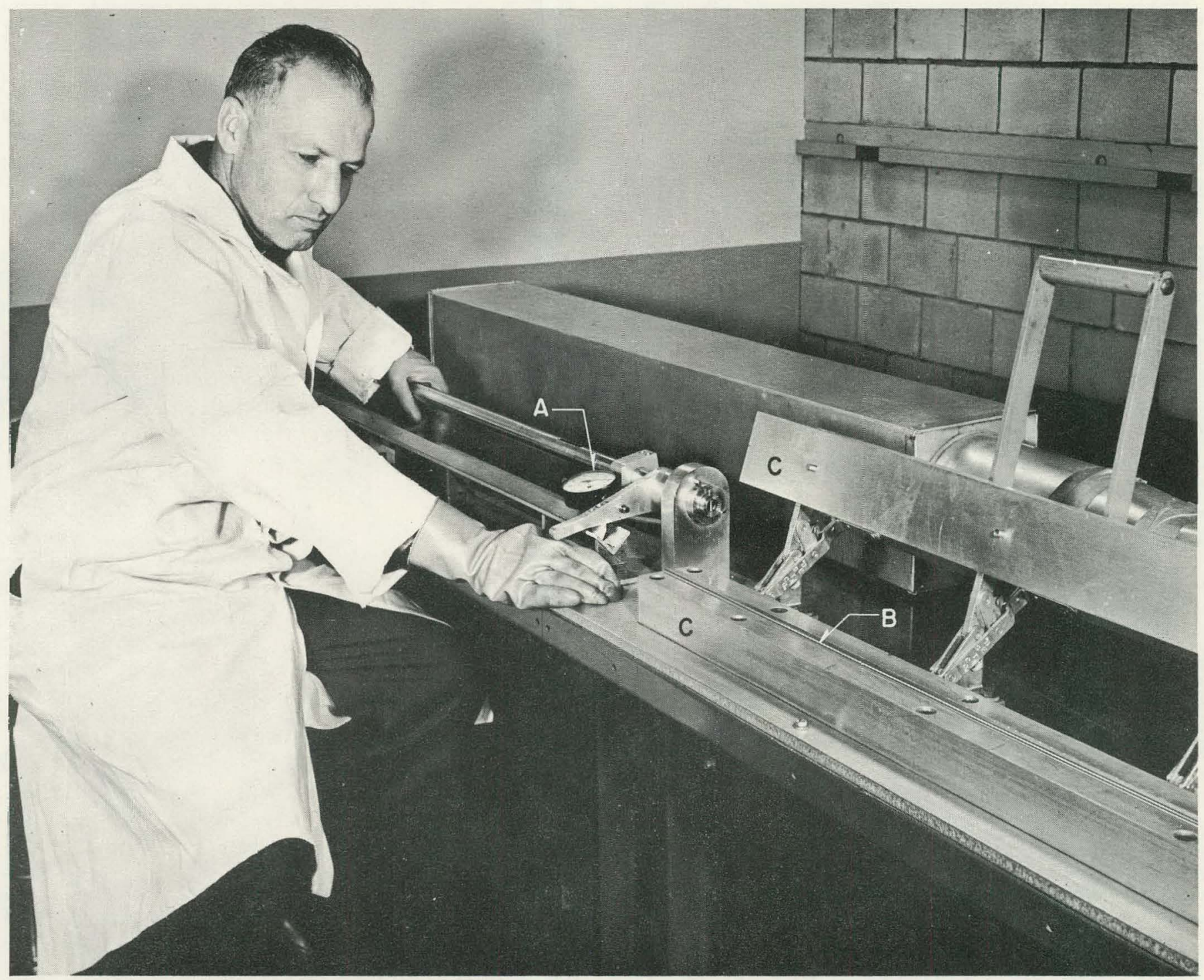

Figure 31

PELLET LOADING EQUIPMENI

The stacked pellets are measured with gage assembly (A) prior to insertion (by pushing on the stack) into tube (B) held in clamping device (C). A straight -ine for ease of loading is assured in this manner. 
Fuel Rod Inspection Data Summary

\begin{tabular}{|l|c|c|}
\hline Variable & $\begin{array}{c}\mathrm{UO}_{2} \text { Weight per } \\
\text { rod (gms) }\end{array}$ & $\begin{array}{c}\mathrm{UO}_{2} \text { Length per } \\
\text { rod (in.) }\end{array}$ \\
\hline Maximum & 580.0 & 48.375 \\
Minimum & 548.0 & 46.675 \\
Range & 32.0 & 0.700 \\
Average & 566.04 & 47.997 \\
$\sigma$ & 4.582 & 0.150 \\
Sample Size & 5483 & 5483 \\
\hline
\end{tabular}

The average weight per foot of the $\mathrm{UO}_{2}$ fuel in the $\mathrm{CRX}$ rods was calculated to be:

$$
\frac{566.042 \times 12}{47.997 \times 453.600}=0.3120 \mathrm{H} / \mathrm{ft} \text { of } \mathrm{UO}_{2}
$$

The distribution curves for the weights per rod of $\mathrm{UO}_{2}$ and the active lengths of each rod are shom in Figures 32 and 33 .

\section{B. End Closure Velds}

End closures of CRX fuel tubes were produced by welding a circumferential bead at the tube-to-end plug joint. Rigid control of the welding current, electrode gap, parts fit-up, and cleanliness of weld area were necessary to produce satisfactory velds.

The tube was held in a rotating collet and end-centering stop while the helium shielded electrode was positioned over the joint.

A total of 10,880 welds were made on the CRX tubes. Two hundred thirty eight visible defects (peel back and/or blor hole, see Figure 37) or $2.2 \%$ were observed.

The visible defects were repaired by subsequent passes or by patching with filler rod and rewelding.

The welding procedure is given in Table XXIII.

A typical end closure Defect Log is shown in lable XXIV. Figure 34 shovs a weld being made and the equipment used in the production of CRX fuel rods. 


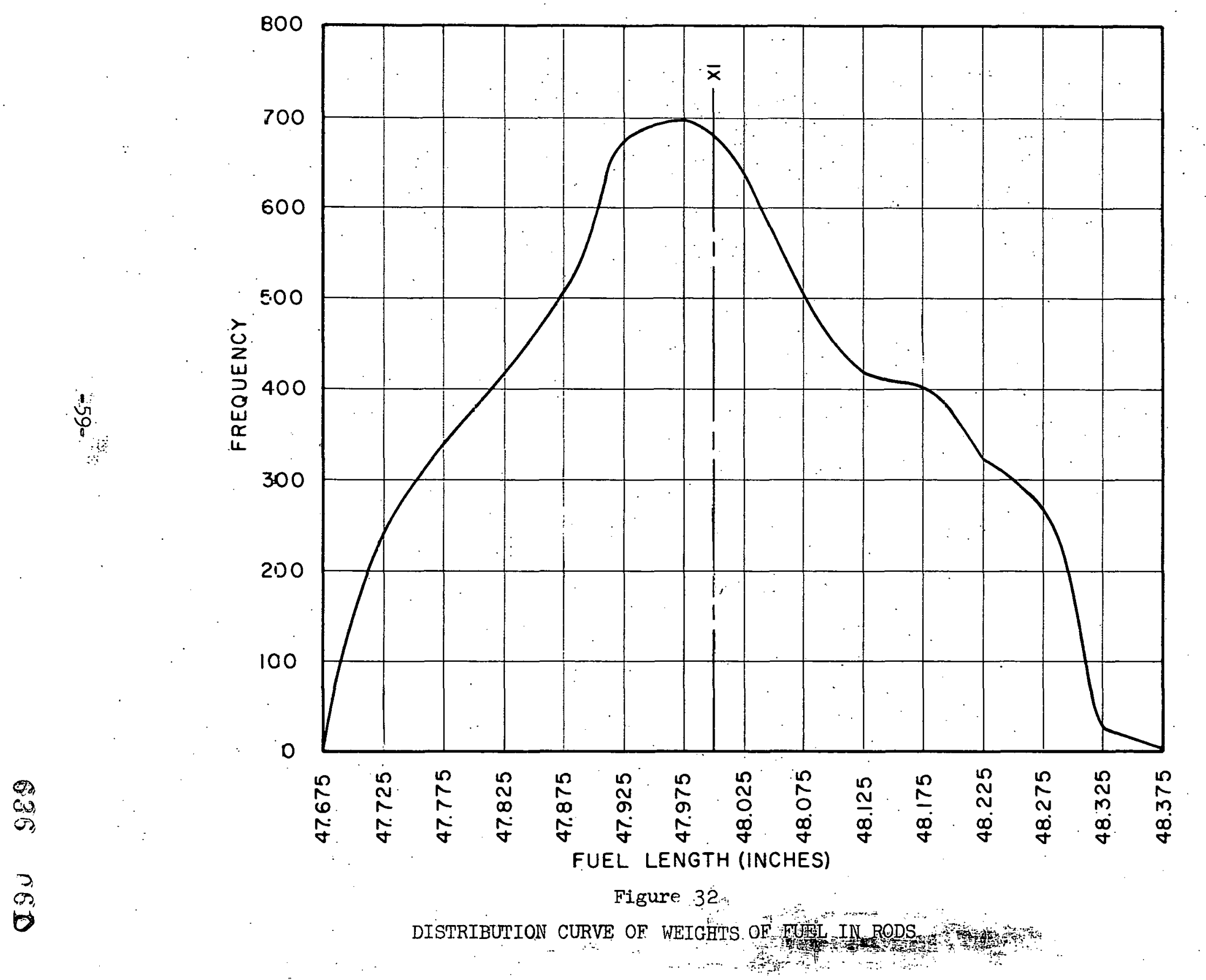




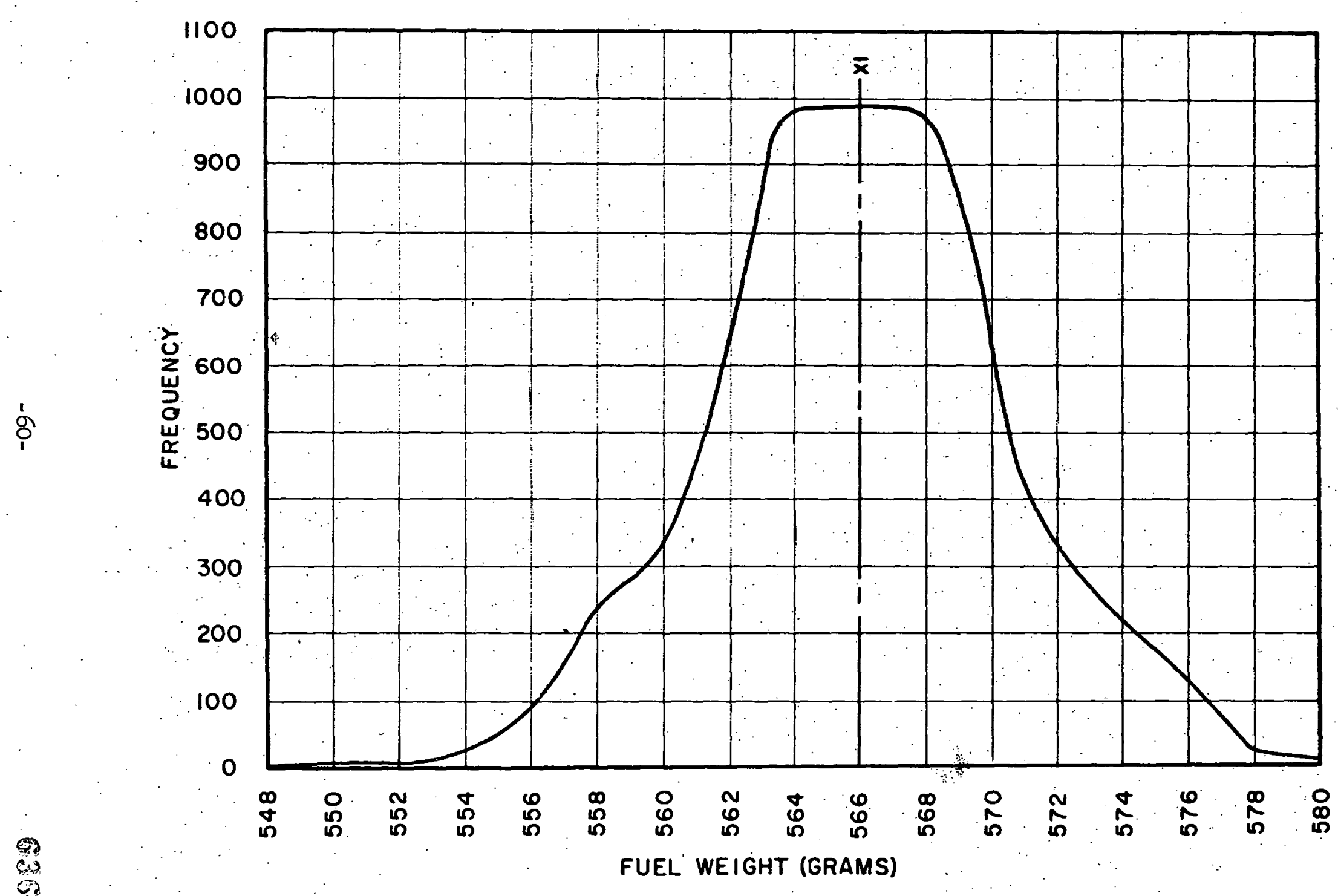

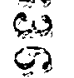

Figure 33

$\frac{3}{7}$

DISTRIBUTION CURVE OF LENGTHS OF FUEL IN RODS 
1. Clean the joint areas so that they are free of grease, oil, fingerprints, and $\mathrm{UO}_{2}$ particles before seating the end plugs. Clean end plugs and tubes prior to loading.

2. After loading the tube with pellets, wipe the open end of the tube with an acetone soaked cotton swab to remove any $\mathrm{UO}_{2}$ particles.

3. Wipe the tube ends with dry G-tips and aliow to air-dry.

4. Inspect the tube and the end plug to assure an interference fit of at least $.0005^{\prime \prime}$. Measure the tube lip to assure that it is less than $.005^{\prime \prime}$ from the end plug shoulder, at all points.

Note: Any noticeable flaring of the tube ends will cause "peelback" of the weld. Flaring which causes tube end ovality greater than $.010^{\prime \prime}$ is cause for rejection.

5. Set aside for further inspection and reseating or. rejection all tubes with improperly seated plugs or flared ends.

6. Place the loaded tubes in the end plug welder and run them against an adjustable positioning stop which shall be set for each type of end plug.

7. Set the electrode gap at $.020^{\prime \prime} \pm .002$ with a feeler gage and offset the electrode point on the end plug side of the joint from .005 to .010".

8. Use a $1 / 16^{\prime \prime}$ diameter, $2 \%$ thoriated tungsten electrode first ground to a sharp point, then slightly flattened.

9. Set the collet rotating motor for a speed of 24 to $25.5 \mathrm{rpm}$ and check the tube for eccentricity.

Note: Reseating the tube in the collet or tapping the end plug lightly with a soft mallet usually removes any eccentricity present.

10. With a helium gas flow of 30 to $40 \mathrm{cfh}$, set the d-c, straight polarity current at 25 amperes for tube thickneobes of .016 to .020".

11. Start the weld by a high frequency, starting voltage as the tube is rotating and then continue welding until a $180^{\circ}$ overlap is made.

Note: A graph of the current and voltage is automatically drawn as the weld is made.

12. As soon as the weld is completed, inspect the weld zone for blowholes or "peelback". Immediately reject all "peelbacks".

13. Small blowholes may be closed by repeat passes over the weld zone. However, if the blowholes are not closed after three passes, remove the tube from the collet and repair with an inert gas shielded metal electrode welding hand torch and a stainless steel filler rod. Grind the filler metal flush with the tube surface and reweld by using the end closure welder.

14. Keep a log (Table XXVI) of all defective welds; stating the tube number, the ond where derect occurred, and the procedure used to repair the weld. 
TABLE XXIV

Defect Log

\begin{tabular}{|c|c|c|c|c|c|c|c|c|c|}
\hline \multirow{2}{*}{$\begin{array}{l}\text { TUBE } \\
\text { NO. }\end{array}$} & \multicolumn{2}{|c|}{ TUBE END } & \multirow{2}{*}{ BLOWHOLE } & \multirow{2}{*}{ PEELBACK } & \multirow{2}{*}{$\begin{array}{l}\text { PASSES TO } \\
\text { REPAIR }\end{array}$} & \multirow{2}{*}{$\begin{array}{c}\text { FILLER ROD } \\
\text { USED }\end{array}$} & \multirow{2}{*}{ REPAIRED } & \multirow{2}{*}{ REJECTED } & \multirow{2}{*}{ REMARKS } \\
\hline & $T$ & B & & & & & & & \\
\hline 5 & $\checkmark$ & & $\checkmark$ & & 3 & $\checkmark$ & $\checkmark$ & & \\
\hline 6 & $\checkmark$ & & & $\checkmark$. & 2 & & $\checkmark$ & & \\
\hline 19 & $\checkmark$ & & $:$ & $\checkmark$ & - & $\checkmark$ & & $\therefore \checkmark$ & $\begin{array}{l}\text { BEVEL } \\
\text { POOR FIT }\end{array}$ \\
\hline 35 & & $\checkmark$ & & $\checkmark$ & 2 & . & $\checkmark$ & & \\
\hline 29 & & $\checkmark$ & $\dot{V}$ & & 3 & . & $\checkmark$ & $\begin{array}{l}\text { NOT } \\
\text { RE JECTED } \\
\end{array}$ & $\begin{array}{c}\text { FOREIGN } \\
\text { MTL. }\end{array}$ \\
\hline 32 & & $\checkmark$ & $\checkmark$ & & 2 & & $\checkmark$ & & . \\
\hline 31 & & $\checkmark$. & $\checkmark$ & & 2 & & $\checkmark$ & . & \\
\hline 30 & $\dot{\jmath}$ & & $\checkmark$ & & 2 & & $\checkmark$ & & \\
\hline 32 & $\checkmark$ & & $\checkmark$ & . & 2 & & $\checkmark$ & & \\
\hline 19 & $\checkmark$ & & & & 2 & & $\checkmark$ & $\begin{array}{c}\text { NOT } \\
\text { REJECTED } \\
\end{array}$ & $\begin{array}{c}\text { GLASSY } \\
\text { iNCLUSION } \\
\text { NOT REPAIRED } \\
\end{array}$ \\
\hline 70 & $\checkmark$ & . & $\checkmark$ & & 3 & & $\checkmark$ & REWELO & \\
\hline 68 & $\checkmark$ & & $\checkmark$ & $\therefore$ & 3 & & $\checkmark$ & REWELO & . \\
\hline 67 & $\checkmark$ & & $\checkmark$ & & 2 & & $\checkmark$ & . & \\
\hline 55 & & $\checkmark$ & $\begin{array}{c}\text { INCOMPLETE } \\
\text { FUSION }\end{array}$ & & 2 & $\cdot$ & $\sqrt{ }$ & & $\begin{array}{l}\text { ECCENTRIC } \\
\text { TUBE Q PLUG }\end{array}$ \\
\hline 92 & $\checkmark$ & & $\checkmark$ & & 2 & & $\checkmark$ & . & : \\
\hline 103 & & $\sqrt{ }$ & $\begin{array}{c}\text { INCOMPLETE } \\
\text { FUSION }\end{array}$ & - & 2 & $\ldots$ & $\checkmark$ & $\therefore$ & . \\
\hline $16 \varepsilon$ & & $\checkmark$ & $\begin{array}{l}\text { INEOMMPLETE } \\
\text { FUSION }\end{array}$ & & 2 & & $\checkmark$ & & \\
\hline 134 & $\checkmark$ & & $\checkmark$ & & 2 & & $\checkmark$ & & \\
\hline 186 & $\checkmark$ & & $\checkmark$ & & & & $\checkmark$ & & \\
\hline 215 & $\checkmark$ & & $\checkmark$ & & & & $\checkmark$ & & BAD FIT \\
\hline 216 & $\checkmark$ & & $\checkmark$ & & & 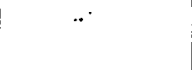 & $\checkmark$ & . & ADD FIT \\
\hline 174 & $\checkmark$ & & $\checkmark$. & . & & & $\checkmark$ & & BAD FIT \\
\hline 196 & $\checkmark$ & & $\sqrt{ }$ & & & & $\sqrt{ }$ & & BAD FIT \\
\hline
\end{tabular}




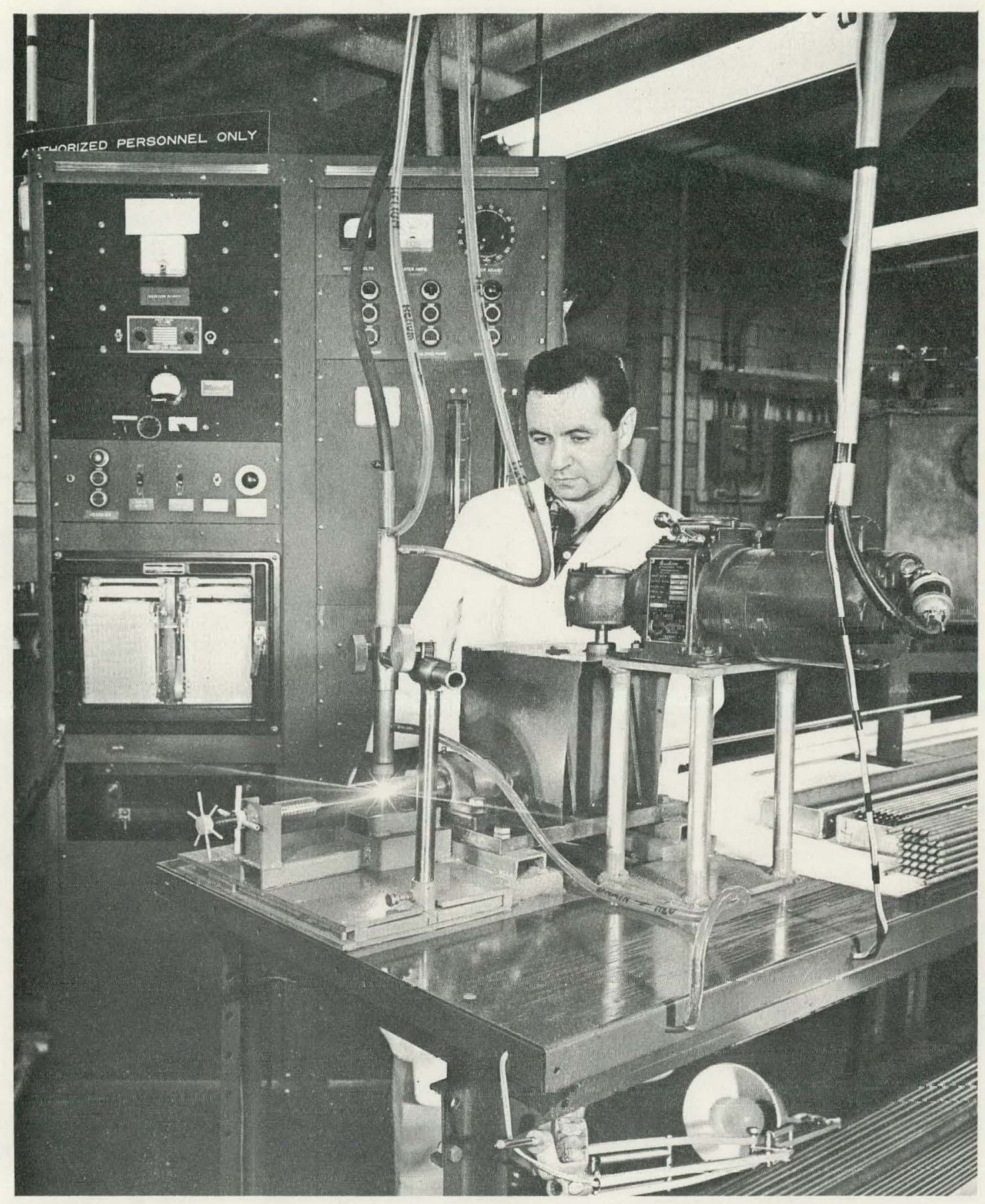

Figure 34

WELDING OF FUEL ROD END PLUG

A fuel rod is sealed by welding end plugs into the tubing. 


\section{Weld Inspection by Radiographic Means}

Defective weldments found by visual inspection vere repaired by the welder. Two other types of defects (porosity and lack of penetration or incomplete fusion) were detected by radiographic means.

Twenty percent (or 2176 welds) of all welds made were radiographed. Sixty seven were found with less than $100 \%$ penetration and 12 were porous velds. It is to be expected that if all 10,880 welds had been radiographed that a total of 395 would be found that were porous or lacked complete penetration (3.6\%). No attempt was made to make this test quantitative because of the application of the fuel rods for the CRX experiment.

A modified Westinghouse Productograph equipped with a 250 constant potential kilovoltage tube with a maximum amperage of 10 milliamperes and a focal spot of 3.5 millimeters was used for inspection. The tube-film distance was constant at 36". A lead lined sleeve was constructed to allow the radiographing of the long fuel rods.

The $\mathrm{X}$-ray procedure is given in Table XXV.

Figure 35 shows fuel rods in place prior to insertion in the productograph. Figure 36 shows velds in position to be radiographed. Note the weld correction form and the position of the penetrameter.

Figure 37 shows tyoical examples of: 1. an acceptable weld, 2 . blowhole defect; 3. "peelback" defect; 4. radiograoh showing porosity; and 5. radiograph showing the lack of weld penetration. 
Procedure for Radiographic Inspection of End Closure Weldments

1. Insert the weldments of 25 fuel rods into the weld correction form (correction form is used to prevent undercutting and scatter of the X-ray beam).

2. Position the correction form parallel to the major axis of the film so that the insidc edge is no more than one inch from the major axis of the film.

3. Place penetrameter whose thickness is $2 \%$ of wall thickness of the total thickness of metal on the film next to the farthest weld from the center.

4. Radiograph all welds twice. ( $90^{\circ}$ rotation after first shot)

5. Use standard 4-1/2" $\times 17^{\prime \prime}$ cardboard cassettes with $.005^{\prime \prime}$ lead antimony screens in front and in back of the film. Use Kodak Type $M$ film.

6. Identify each weld by the use of lead numbers.

7. Use the following parameters:

a. $190 \mathrm{KVCP}$

b. 600 miliampere seconds exposure

c. I mm thick aluminum source filter

d. 36" target to film distance

e. cardboard casscttes fronl and back screens $0.005^{\prime \prime}$ thick lead-antimony

8. Develop films for 8 minutes using Kodak Industrial developer and fixer. Wash all exposed negatives with Kodak Photo-flo wetting agent prior to drying.

9. Read the negatives by using a w'Luorospot high-intensity illuminator in a subdued background lighting. 


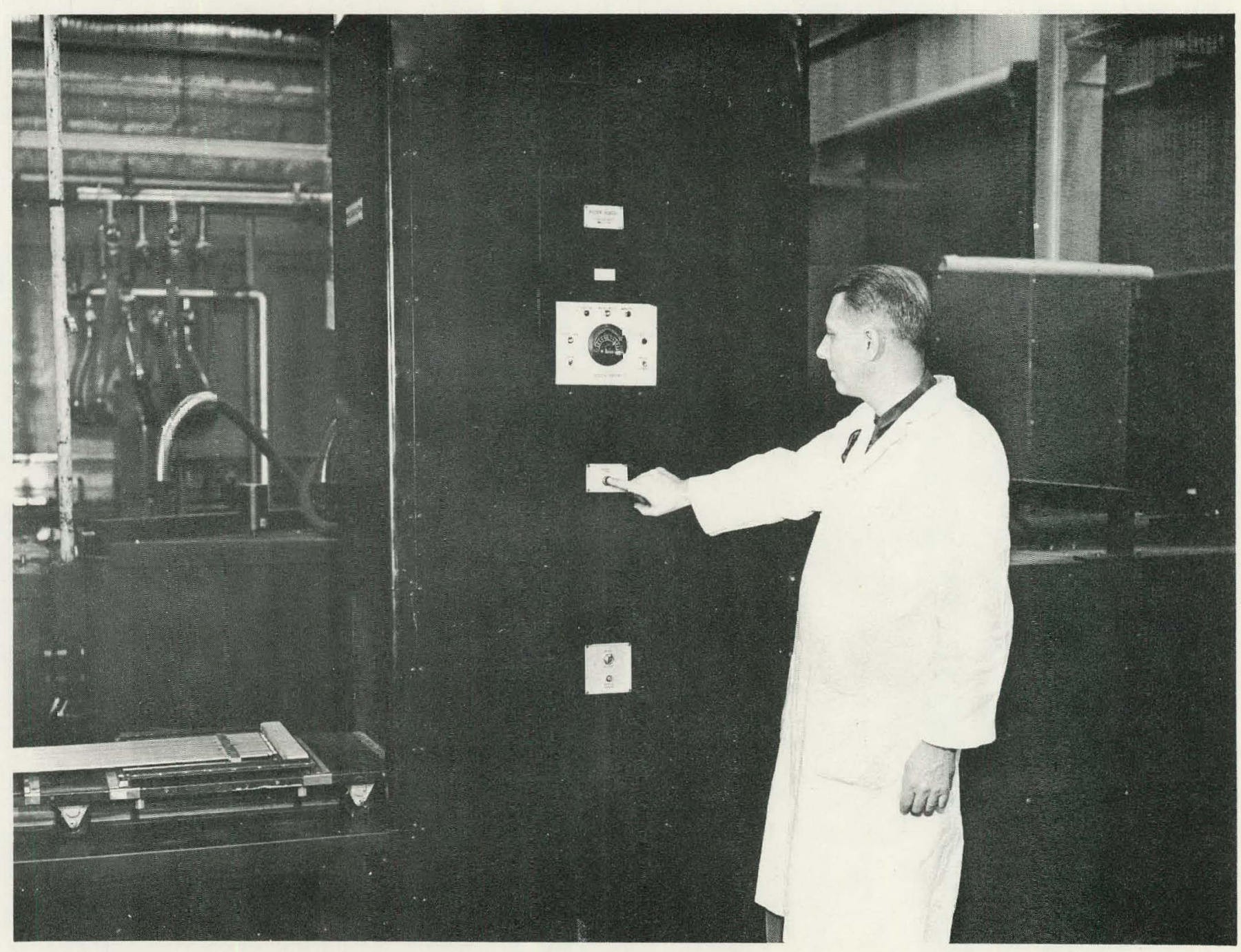

Figure 35

FUEL RODS BEINC- INSERTED IN X-RAY MACHINE

The rods to ke $\mathrm{X}$-rayed are placed on dollies to insure froper placement ir the machine. 


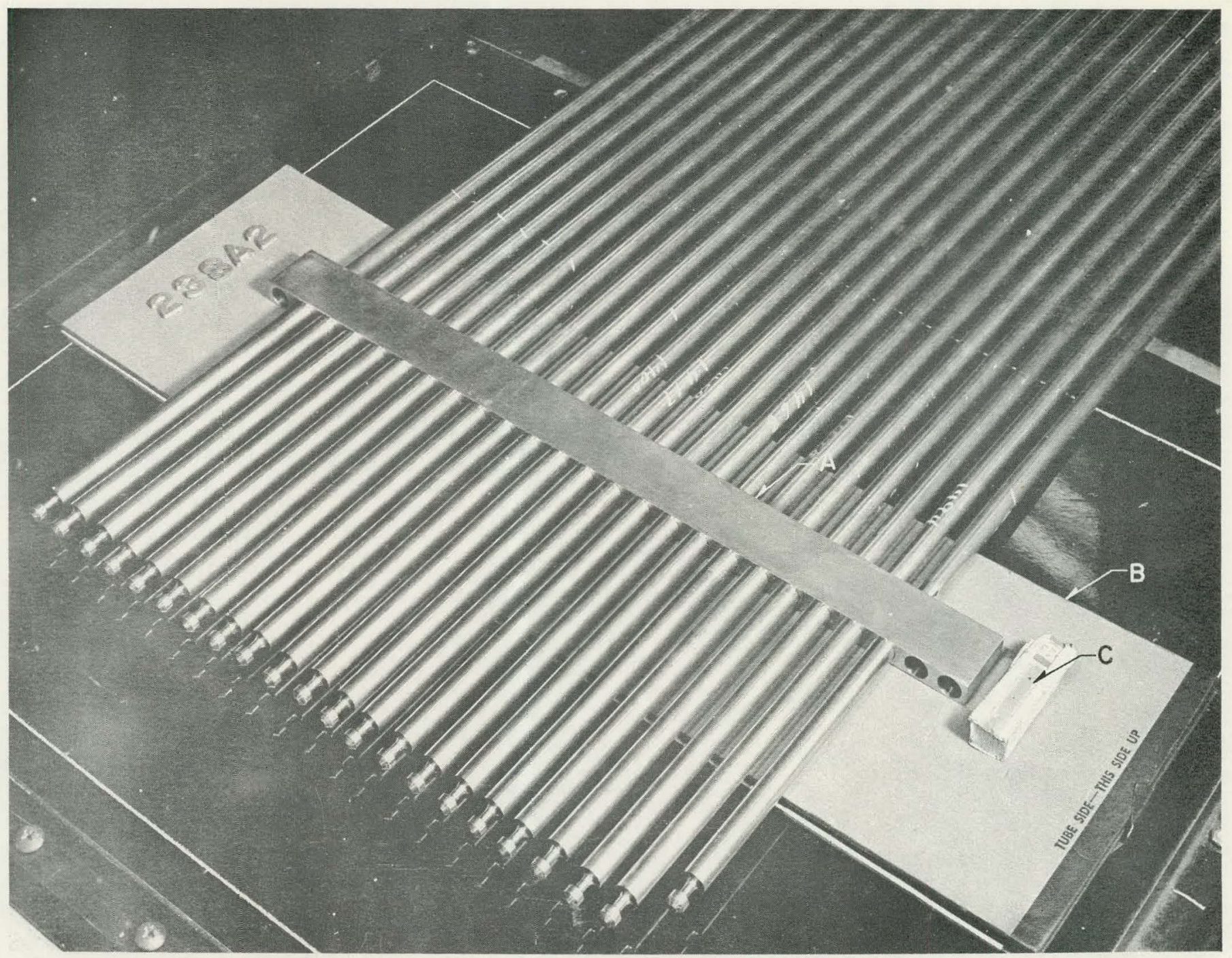

a

क)

2
Figure 36

FUEL RODS READY FOR X-RAY

Completed fuel rods are radiographed by placing the welds in the correction form (A) over the

film holding cassettes (B). The sensitivity of the exposure is measured by the use of a penetrameter (c) $0.005^{\prime \prime}$ thick. 

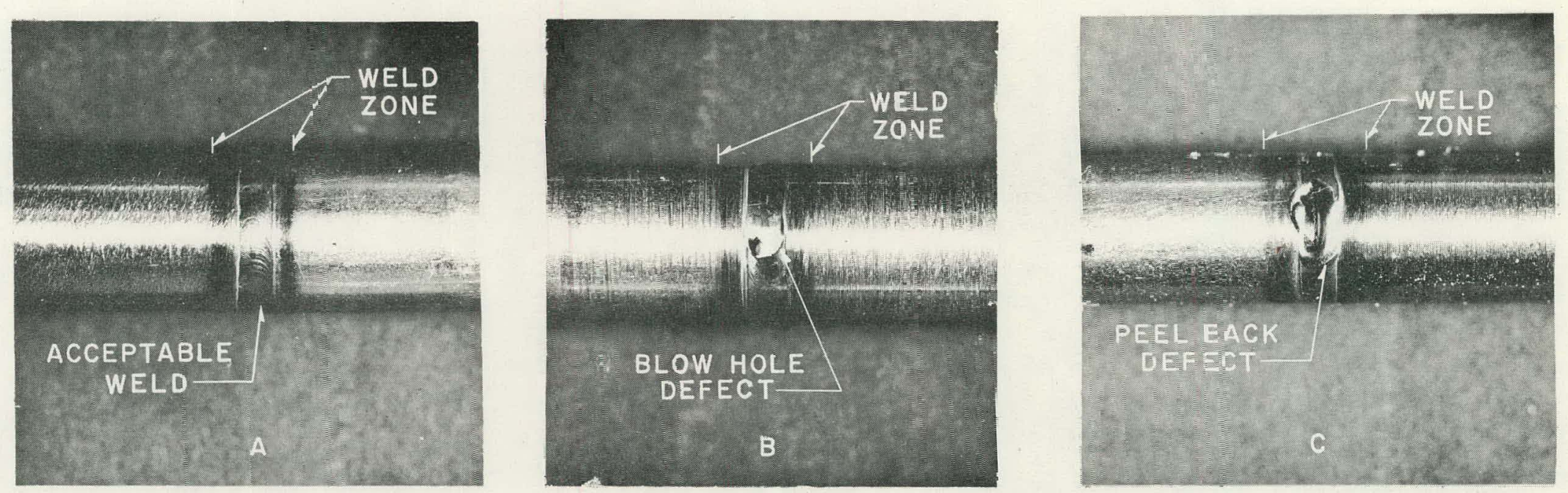

ळू
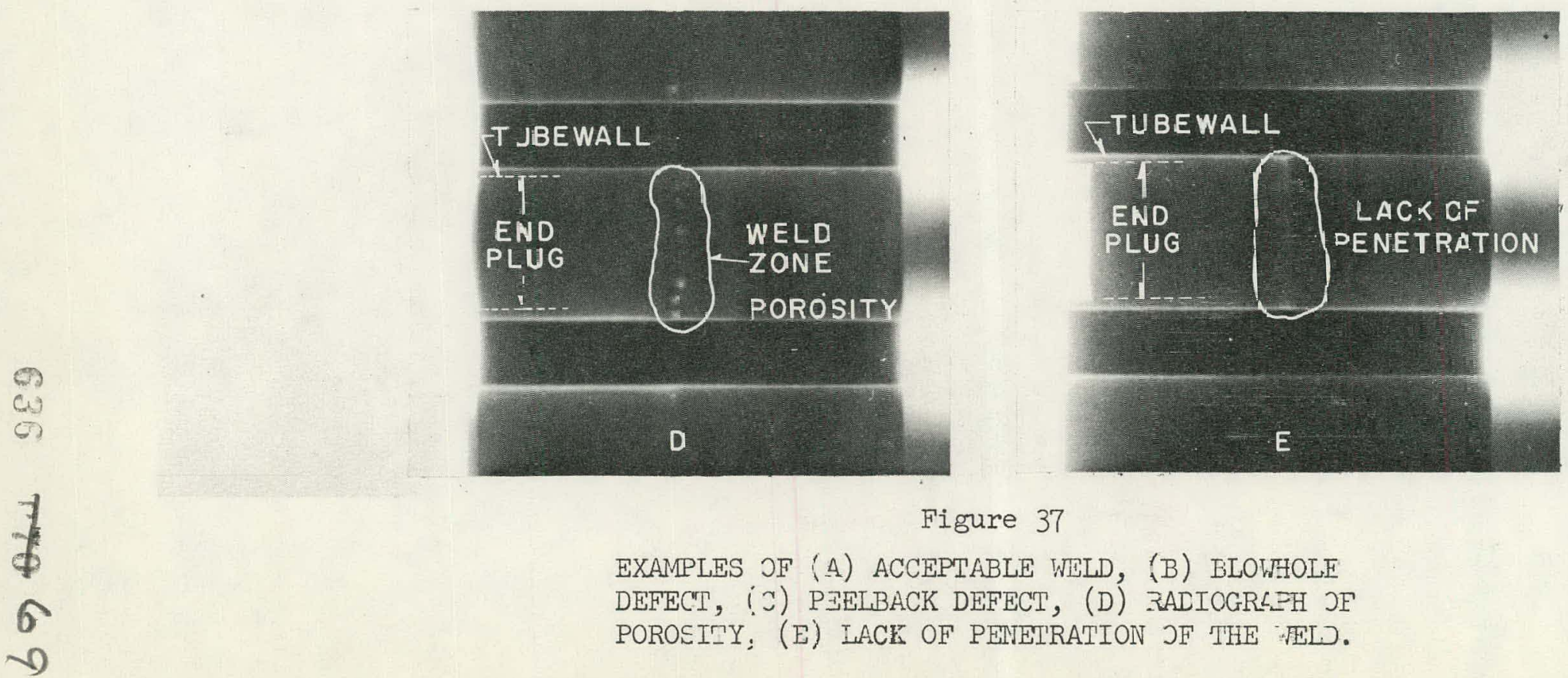

Figure 37

EXAMPLES OF (A) ACCEPTABLE WELD, (B) BLOWHOLE DEFECT, ( ( ) P $3 E L B A C K$ DEFECT, (D) KALIOGRL POROSITY; (E) LACK OF PENEIRATION JF THE WE. 
VII. Surnmary

The 5509 fuel rods made for the YAEC critical experiment used 3,114,733.5 grams of acceptable $\mathrm{UO}_{2}$ pellets. To produce these pellets 3,463,409.1 grams of $\mathrm{UO}_{2}$ was required. The total yjeld from the pellet fabrication process and the fuel rod fabrication process was $90.0 \%$. Accountability records show that the yield in the fuel manufacturing step alone was $98.8 \%$. The losses sustained are: 1 ." scrap generated-0.38\%, 2 . unaccountable (dust collectors, clean up waste) - $0.12 \%$ and 3. all other reasons (chemical analysis, experimentation, retained sample) - $0.7 \%$.

There was good agreement between chemical analysis performed at MCW and at WAPD on $\mathrm{UO}_{2}$ powder samples.

Inspection of the tubes used resulted in the following average flgures:

Outside Diameter
Inside Diameter
Wall Thickness
Length
Weight

0.3384 inches

0.3062 inches

0.0160 inches

49.420 inches

104.453 grams

The veight of one foot of tube was calculated to be $0.056 \#$. Inspection of the three major types of end plugs resulted in the following average figures:

$\begin{array}{cccc}\text { End Plug } & \frac{\text { Length }}{} & \text { Weight } & \text { Insert Diamet } \\ \text { Item } 1 & 5.7510^{\prime \prime} & 64.410 \mathrm{gms} & 0.3085^{\prime \prime} \\ \therefore 2 & 6.2487^{\prime \prime} & 70.429 \mathrm{gms} & 0.3086^{\prime \prime} \\ \therefore 3 & 4.6067^{\prime \prime} & 50.036 \mathrm{gms} & 0.3087^{\prime \prime}\end{array}$

Inspection of the pellets resulted in the following average figures:

$\begin{array}{ll}\text { Diameter } & 0.3000 \text { inches } \\ \text { Length } & 0.5989 \text { inches } \\ \text { Weight } & 7.0699 \text { inches } \\ \text { Density (wet) } & 93.08 \% \text { theoretical }\end{array}$

The pellet-to-tube gap (diameter differences) averaged 0.0060 " with a maximum measurement of 0.0085 inches and a minimum measurement of, $0.0035 . "$.

The average weight of $\mathrm{UO}_{2}$ in a completed rod was 566.04 grams. The average length of $\mathrm{UO}_{2}$ in a completed rod was 47.997 inches. The average weight per foot of $\mathrm{UO}_{2}$ per rod was calculated to be 0.3120 lbs 'ft.

There were 10,880 welds made (some special rods were not welded but rather vere sealed using 0-rings): During welding a total of 238 visual defects were discovered and repaired. X-ray inspection data revealed that if every weld that had been macte vere radiographed, the re would have been 395 that vere defective. 


\section{Acknowledgement}

The author wishes to acknowledge the work done. by the various personnel of WAPD who made it possible to collect the data for this report. Mr. R."Winchell, Chemistry and Ceramics, followed the fabrication of pellets, Mr. P. P. King, Metallurgy Section, followed the welding. Mr. N. Gordon, Technical Operations, supervised the analytical work. C. Benton, Drafting, constructed the density nomograph. Messrs. B. Hanson and $\mathrm{R}$. Bremmer supervised the production, accountability, inspection and developed the equipment used. 